\title{
Elina Ligere
}

\section{CLINICAL, ECHOCARDIOGRAPHIC AND BIOMECHANICAL ASPECTS OF COARCTATION OF THE AORTA IN INFANTS IN LATVIA}

Summary of Doctoral Thesis to Obtain a PhD Degree in Medicine Speciality - Pediatric Cardiology 
Elina Ligere

\title{
CLINICAL, ECHOCARDIOGRAPHIC AND BIOMECHANICAL ASPECTS OF COARCTATION OF THE AORTA IN INFANTS IN LATVIA
}

\author{
Summary of Doctoral Thesis \\ to Obtain a PhD Degree in Medicine
}

Speciality - Pediatric Cardiology

Riga, 2013 
The promotion thesis was carried out at The University Hospital for Children, Clinic for Pediatric Cardiology and Cardiac Surgery

The biomechanical experiments were performed in the Laboratory of Biomechanics of Rīga Stradiņš University

Scientific supervisors:

Dr. habil. med., Professor Aris Lācis, Clinic for Pediatric Cardiology and Cardiac Surgery, University Hospital for Children Riga

Dr. habil. ing. sc., Professor Vladimir Kasyanov, the Laboratory of Biomechanics of Rīga Stradiṇš University

Official reviewers:

Dr. med,. Professor Oskars Kalējs (Rīga Stradiņš University)

Dr. med,. Leading researcher Indulis Kukulis (University of Latvia)

Dr. med,. Vita Zīdere (United Kingdom)

Defense of the promotion thesis will take place on November 26, 2013 at 13.00 at Senate hall of Rīga Stradinšs University in open meeting of Promotion Council of Medicine

The promotion thesis is available at the Rīga Stradinš University Library`s home page: www.rsu.lv

The promotion thesis was done under support of the ESF Project "Support to doctoral students for acquiring the study program and obtaining a scientific degree at Rīga Stradiņš University ”
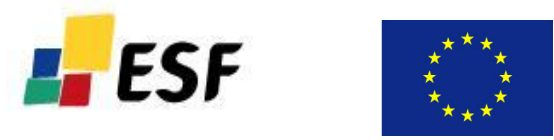

Secretary of Promotion Council:

Dr. habil. med., Līga Aberberga-Augškalne 


\section{TABLE OF CONTENTS}

ABBREVIATIONS...........................................................

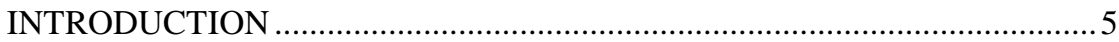

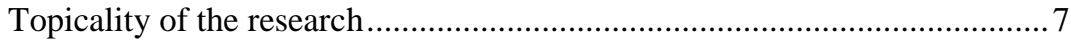

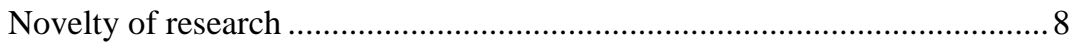

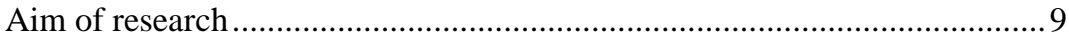

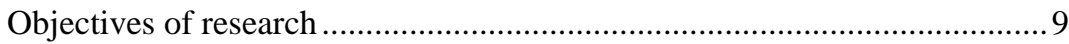

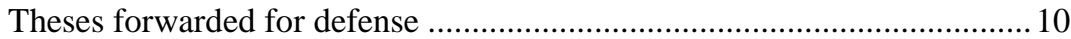

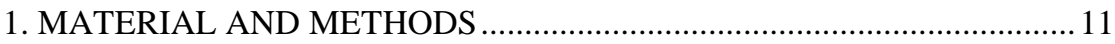

1.1. Statement of the study period.............................................................. 11

1.2. Characterization of the clinical study group......................................... 12

1.3. Echocardiographic examination of the study patients .......................... 16

1.4. Material and methods of the biomechanical study of the aortic arch ... 18

1.5. Statistical analysis of the data ............................................................ 21

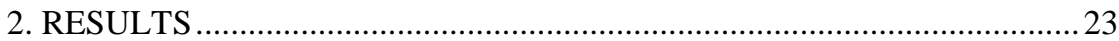

2.1. The prevalence of coarctation of the aorta in neonates in Latvia

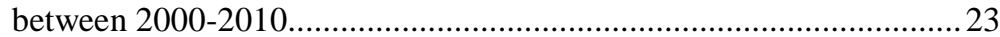

2.2. Recognition of ductus dependent aortic coarctation in Latvia

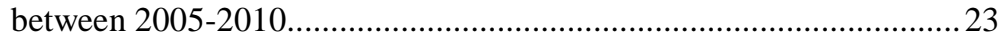

2.3. The results of surgical correction of coarctation in infants in

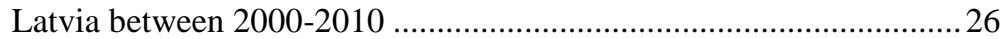

2.4. Echocardiographic study of patients following surgical correction of aortic coarctation within the first year of life.

2.5. The biomechanical properties of different modalities of surgically corrected aorta in neonates and infants ................................................40

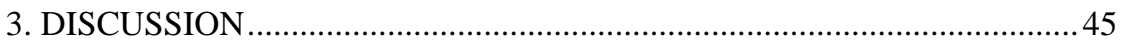

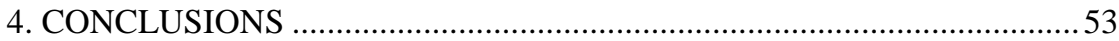

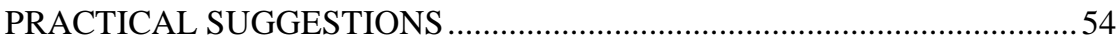

PUBLICATIONS AND PRESENTATIONS ON THE

RESEARCH THEME. 


\section{ABBREVIATIONS}

Ao $\quad-$ aorta

AoCo - aortic coarctation

AoreCo $\quad-$ recoarctation of the aorta

AoS $\quad-$ Aortic stenosis

ASD $\quad-$ atrial septal defect

AVSD - atrioventricular septal defect

CHD - congenital heart disease

CI - confidence interval

CT - computed tomography

CWD - continuous wave dopplerography

DILV - double inlet left ventricle

DORV - double outlet right ventricle

EchoCG - echocardiography

EF $\quad-$ ejection fraction

ETE - anastomosis end-to-end

EETE - extended anastomosis end-to-end

FS $\quad-$ fractional shortening

HLHS - hypoplastic left heart syndrome

IVSd - ventricular septum in diastole

LV - left ventricle

LVEDD - left ventricle end diastolic dimension

LVESD - left ventricle end systolic dimension

LVM - left ventricle mass

LVMi - left ventricle mass index

LVPWd - left ventricle posterior wall in diastole

MR - magnetic resonance

MS $\quad-$ mitral stenosis

PBA - primary balloon angioplasty

PDA $\quad-$ patent ductus arteriosus

PgE1 - Prostoglandin E1

Pg max. $\quad-$ maximum presure gradient

PH $\quad-$ pulmonary hypertension

PS - pulmonary stenosis

PWD - - pulse wave dopplerography

PWD D $\quad-$ minimum diastolic forward flow velocity PWD

PWD S - maximum sistolic flow velocity PWD

PWD S/D - relation of maximum sistolic/minimum diastolic flow PWD

SFA $\quad-$ subclavian flap aortoplasty

TGA $\quad-$ transposition of the great vessels

$\mathrm{X}^{2}-$ chi square

VSD $\quad-$ ventricular septal defect 


\section{INTRODUCTION}

Congenital heart disease (CHD) affects 8-12 per 1000 live-born infants and is one of the most common and serious congenital anomalies. Approximately one quarter of these children will have critical CHD which requires surgery or catheter intervention within the first year of life (Chang et al., 2008; Hoffman et Kaplan, 2002).

Aortic coarctation (AoCo) - narrowing of the descending aorta usually just distal to the origin to the left subclavian artery, accounts for 6-10\% of CHD with a prevalence of 36 (29-49)/100 000 newborn infants (Park, 2008; Dolk et al., 2010). According to the data European surveillance of congenital anomalies, the prevalence of AoCo during the years 2005-2009 in the summary from all the registries ranged between 2.49-3.01 per 10.000 live-born babies. It manifests as a leading CHD in approximately 64\% of the infants with AoCo soon after birth (Samanek et Voriskova, 1999).

The studies from the literature about belated diagnoses of CHD as a cause of death in newborn (Chang et al., 2008; Massin et Dessy, 2006) showed aortic coarctation and hypoplastic left heart syndrome (HLHS) as the most common diagnoses in these patients. Half of the babies leaving the birth hospital with undiagnosed CHD had AoCo (Wren et al., 2008). Many newborns with severe CHD are discharged from maternity units without the problem being recognized despite the modern diagnostic methods available (Mahle et al., 2009; Riede et al., 2010). Significant physiologic compromise as a sequel to unsuspected CHD affects 1 of 15.000 to 1 of 26.000 live-born babies (Shulz et al., 2008). The problem becomes topical also due to the trend towards early discharge and home deliveries. The CHD which determines ductus dependent systemic circulation is diagnosed later more often than those with ductus dependent pulmonary circulation manifesting with cianosis (Mellander et 
Sunnegardh, 2006). The everyday work in clinics leads to the conception that ductus dependent CHD is a substantial cause of the morbidity and mortality of newborns and small infants in our country and the problem is therefore worth studying.

There is no national registry of CHD in Latvia. Data on the epidemiology of CHD in newborns in our country could be acquired only through data study from such sources as the registry of CHD of the Clinic for Pediatric Cardiology and Cardiac Surgery and the Department of Pathology of the University Hospital for Children. The University Hospital for Children is the only institution in our country where pediatric patients with CHD are treated and followed up, so the data represent the overall data for the country`s inhabitants.

There has been significant improvement in the diagnostics and possibilities fot treatment of CHD around the world (Kugler et al., 2009; Tchervenkov et al., 2008) and in Latvia during the last decades, and therefore the prevention of preoperative morbidity and mortality has become more important. The surgical correction of aortic coarctation was commenced and has developed since the 1960`s (Brown et al. 2009; Burch et al., 2009; Hager et al., 2009; Jonas, 2004; Kaushal et al., 2009; Karamlau et al., 2009; Pandey et al., 2006; Sudarshan et al., 2006; Thomson et al., 2006). There is no one universal method of treatment due to the differences in the anatomy of the lesion and concomitant intracardiac pathologies. Interventional balloon angioplasty was commenced in cases of AoCo in the 1980`s. The long term results in cases of primary transvasal AoCo correction in neonates and small infants are still controversial (Fiore et al., 2005; Fruh et al., 2011; Peres et al., 2010; Walhout et al., 2004). An analysis of the literature and clinical data to evaluate more appropriate tactics for neonates is necessary.

There is a risk of recoarctation, arterial hypertension, aneurism formation and aortic dissection in cases of AoCo despite successful surgical correction in early infancy (Beekman, 2008; Rosenthal, 2005). 
There is limited data about the biomechanical properties of the aorta in neonates and small infants. One can find information about the biomechanical properties of the aorta in experiments with animals (Huang et al., 2006; Kassab et al., 2006; Manon et al., 2012). There are aging processes, biomechanical changes caused by atherosclerosis and aneurism formation processes in the aorta described, but little information about the biomechanics in young individuals (Guinea et al., 2010). Tests in vitro can be carried out to investigate the biomechanical properties of the arterial wall (Hayash et al. 2001).

\section{Topicality of the research}

Congenital anomalies are one of the leading causes of neonates in developed countries (Chang et al., 2008; Mahle et al., 2009). There are still high infant mortality rates in Latvia: 7.8/1.000 in 2005 and 5.7/1.000 in 2010 (the number of deaths of infants under one year old in a given year per 1.000 live births in the same year) (data from the Central Statistical Bureau of Latvia). The timely recognition of CHD probably will decrease these numbers, especially, in cases when surgical correction of the pathology is possible. There are no data about AoCo as the cause of morbidity and mortality of newborn in our country.

The number of patients surviving after correction of congenital heart diseases in infancy has increased due to progress in diagnostics, surgical and interventional technologies in pediatric cardiology. These patients make up the group of the patients with grown up congenital heart diseases (GUCH).

The study contains an analysis of patients with coarctation of the aorta

which is described as the $7^{\text {th }}$ most frequent CHD. For that reason, even in a country with a small population and a low birth rate, every pediatrician, 
echocardiography specialist and general practitioner could meet a patient with unrecognized or previously surgically corrected AoCo. Additional knowledge in the evaluation and care of these patients is needed. The later results of surgical correction of AoCo should be evaluated taking into account the method of correction used.

Nowadays, echocardiography serves as the primary non-invasive tool for the evaluation of a pediatric cardio-vascular system before and following the surgical correction of CHD. It is important to analyse the echocardiographic findings of the particular CHD before and after surgical correction and during the follow-up to promote the timely recognition of possible complications.

An investigation of the biomechanical properties of the aorta in biomechanical experiments allows one to understand the influence of the technique of surgical correction on the further biomechanics of the vascular wall and possible causes of haemodynamic changes as well as changes within the arterial wall during angioplasty.

There are only a few previous studies of congenital heart diseases in the pediatric population in our country.

\section{Novelty of research}

1. The results of the study show new information about the prevalence of coarctation of the aorta in Latvia during the years 2000-2010.

2. The factors influencing morbidity and mortality in patients with aortic coarctation being diagnozed and treated within the first year of life in our country since 2000 , with a follow-up period up to 2011 , were analyzed for the first time. 
3. The study discloses a summary of echocardiographic findings in neonates and infants with aortic coarctation at the time of diagnosis and during follow-up in the medium long term after surgical correction of the lesion in Latvia in the last decade.

4. The research contains a unique biomechanical study of native and surgically corrected infantile aorta.

\section{Aim of research}

The aim of the research was to establish an optimum strategy for the treatment of aortic coarctation in neonates and small infants in Latvia.

\section{Objectives of research}

1. To investigate the prevalence of coartation of the aorta in neonates in Latvia within years 2000-2011.

2. To study and analyse the factors affecting morbidity and mortality in infants with coarctation of the aorta.

3. To improve the echocardiographic protocol for detailed examination of infants with coarctation before and following surgical correction of the lesion and to analyse echocardiographic findings in infants with coarctation diagnosed and treated within the first year of life.

4. To investigate the later results of aortic coarctation being corrected in neonates and small infants. 
5. To carry out biomechanical experiments to compare the biomechanical properties of different anastomoses used for the correction of coarctation in material form autopsies.

6. To work out practical recommendations for the diagnostics and treatment of coarctation in neonates and small infants.

\section{Theses forwarded for defense}

1. The prevalence of aortic coarctation does not differ from the data of other European countries, however, in combination with concomitant intracardiac pathologies, still cause high mortality in the early age group.

2. The biomechanical properties of surgically corrected infantile aorta are diverse in cases of various surgical techniques.

3. Aortic coarctation should be looked on as a complex cardio-vascular syndrome with a need for regular systematic life-long follow-up due to the risk of multiple modifiable complications (recoarctation, arterial hypertension, formation of aortic aneurysm). 


\section{MATERIAL AND METHODS}

The research was carried out in the Clinic for Pediatric Cardiology and Cardiac Surgery of the University Hospital for Children in Riga, Latvia between the period from 2008 to 2012. The study was approved by the Ethics Comittee of the University Hospital for Children. The research consisted of clinical and biomechanical parts. Biomechanical experiments were performed in the Laboratory of Biomechanics of Riga Stradins University.

\subsection{Statement of the study period}

Before the study, all publications about the treatment of coarctation of the aorta in neonates and small infants in Latvia were studied (Lācis et Volkolakovs, 1994; Volkolakovs et Lācis, 1987). An analysis of the surgical registry of the Clinic for Pediatric Cardiology and Cardiac surgery of the University Hospital for Children (since 1996) and the surgical registry of heart surgey of the Pauls Stradins Clinical University Hospital (for 1984-1994) on surgical correction of coarctation within the first year of life was carried out. The surgical correction of aortic coarctation has been performed in Latvia since 1964. It was commenced at the Pauls Stradins Clinical University Hospital. After the establishment of the Latvian Cardiology Center for Children in 1994 (surgery commenced in 1997), it was reorganized later as the Clinic for Pediatric Cardiology and Cardiac Surgery of The University Hospital for Children in 2006 heart surgery for children in our country is only performed there. There were only 32 children operated on within the first year of life during the years1964-1985, with an overall mortality of $25 \%$ (Volkolakov et Läcis, 1987). There were 30 children up to the age of 12 months (only 1 
neonate) operated on due to coarctation within the years 1984-1994. There were 9 children operated on due to coarctaion within the first year of life during the years 1997-1999 (8 infants and 1 neonate).

As the small number of neonates operated on due to coarctation up to the year 2000 does not allow the analysis of aortic coarctation as ductus dependent CHD, the period of time from 1 January, 2000 to 31 December, 2010 was chosen for the research.

\subsection{Characterization of the clinical study group}

To explore the prevalence of AoCo in neonates in Latvia, data from all patients $(n=100)$ with aortic coarctation corrected at the Clinic for Pediatric Cardiology and Cardiac surgery of the University Hospital for Children during the time from 1 January, 2000 to 31 December, 2010 were reviewed. From these patients, the 74 with coarctation corrected within the first year of life were selected. The patients were neonates up to 28 days of life and infants from the 29th day of life to 12 months old (Figure 1.1.). All the neonates and infants with a diagnosis of coarctation $(n=8)$ who had died without an operation or during the correction of severe combined intracardiac pathology were selected from the necropsy registry. The data from these 8 patients were not further analysed in detail because their deaths were connected mainly to a complicated intracardiac pathology. The patients with hypoplastic left heart syndrome (HLHS) were not included in the study. The data were analysed in association

with the birth rates in our country for the named period (data from Central Statistical Bureau of Latvia for the years 2000-2010). 


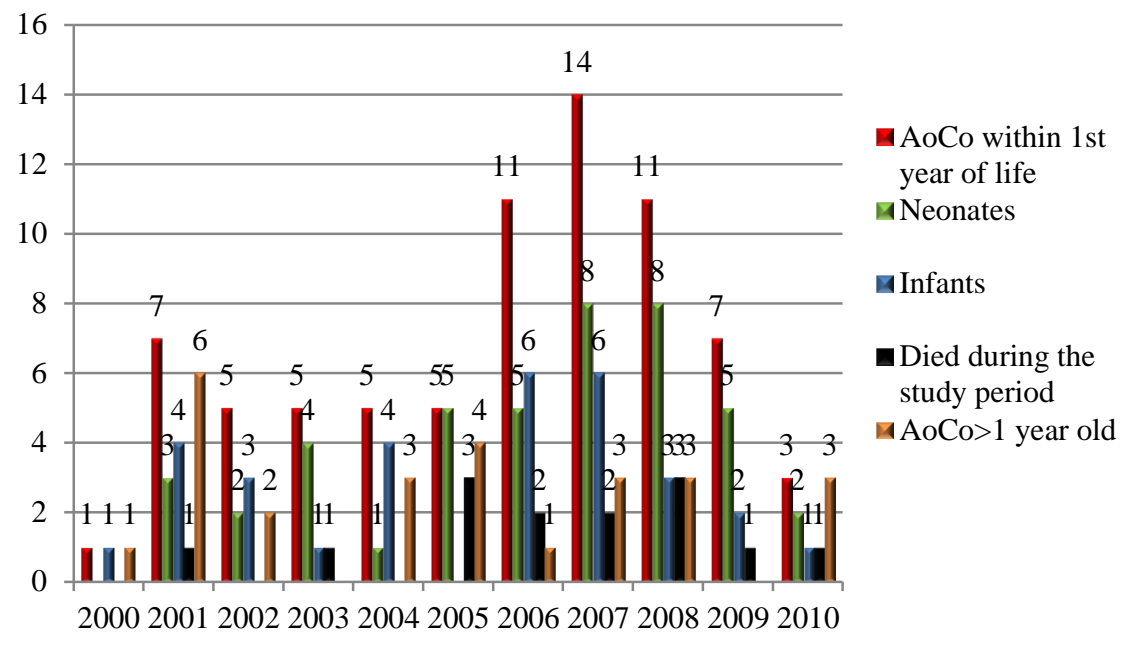

Figure 1.1. Distribution of children with aortic coarctation corrected in Latvia between the years $2000-2010(n=100)$ according to age

To explore AoCo as a ductus dependent CHD in neonates and the influence of a belated diagnosis on a patient's condition and outcomes, data from patients diagnosed with AoCo up to the age of 2 months in the period from 1 January, 2005 to 31 December, 2010 were analysed. The more recent period was chosen because of the better overall diagnostics and the more frequent use of Prostoglandin E1 in perinatal centres in Latvia. An analysis of the case histories was carried out. The information collected included a referral source and diagnosis, data about prenatal care, the timing and presentation of the disease, a description of the cardiac anatomy, preoperative laboratory data, and clinical events. The data from patients referred from the birth clinics (early diagnosis) and those admitted to hospital after their discharge home (late diagnosis) were compared.

To explore the outcomes of surgical correction of AoCo, case histories, outpatient case histories and echocardiography data were studied for all the patients $(n=74)$ undergone surgical correction of coarctation within the first 
year of life between the years 2000-2010. The patients were divided into 3 groups according to the additional concomitant intracardiac pathology: I - the patients with simple AoCo with and without atrial septal defect (ASD), II - the patients with AoCo and VSD, III - the patients with complex AoCo (in combination with different concomitant intracardiac pathologies).

There were 14 deaths from the 74 patients with AoCo corrected within the first year of life. From the remaining 60 patients, 59 patients were followed-up further. In one case, parents refused to participate in the study, the patient was not examined in our clinics and the data were not analysed.

The patients were followed-up $70.7 \pm 33$ months after correction of the coarctation of the aorta (minimum 20, maximum 131 months). The selection of patients for the research and the outcomes in connection with the method of the surgical correction of the lesion are given in figure 1.2. Echocardiographic examination and measurements of arterial pressure were performed during every visite and each patient's hight and weight was analysed using the Normatives of Physical Development of Children in Latvia (Krüminga un Kokare, 2005). 
Infants with AoCo up to the age of 12 months born between 2000-2010

$$
\text { ( } n=82)
$$

Newborn AoCo prevalence analysis in Latvia during years 2000-2010

8 of these patients with severe concomitant combined intracardiac anomalies

died without an operation or during simultaneous correction of AoCo and intracardiac pathology-excluded from further study

\begin{tabular}{|c|c|c|c|c|}
\hline \multicolumn{3}{|c|}{$\begin{array}{c}\text { Study patients } \\
\text { AoCo corrected in University Hospital for } \\
\text { Children in Riga within the first year of life } \\
\text { between } 2000-2010 \\
(n=74)\end{array}$} & \multicolumn{2}{|c|}{$\begin{array}{l}\text { Years } 2005-2010(n=45) \\
\text { AoCo corrected within } \\
\text { first } 2 \text { months of life } \\
\text { (recognition of AoCo as a } \\
\text { ductus dependent CHD) }\end{array}$} \\
\hline \multicolumn{2}{|l|}{$\begin{array}{r}12 \text { of these pa } \\
\text { intraca } \\
\text { (corrected d }\end{array}$} & \multicolumn{2}{|c|}{$\begin{array}{l}\text { Alive at the end of } \\
\text { the study }(n=60) \\
\text { Analyzed } n=59 \\
\text { Parents refuse to } \\
\text { participate } n=1\end{array}$} & $\begin{array}{c}\text { Concomitant } \\
\text { intracardiac } \\
\text { pathology } \\
\text { corrected } \\
\text { within the } \\
\text { study period } \\
n=10\end{array}$ \\
\hline $\begin{array}{l}\text { Early death } \\
\text { Within } 30 \text { days } \\
\text { following the } \\
\text { operation } \\
(n=7,9 \%)\end{array}$ & $\begin{array}{l}\text { Late death } \\
\text { During the } \\
\text { study period } \\
(n=7,9 \%)\end{array}$ & & & $\begin{array}{c}\text { No data about } \\
\text { recoarctation } \\
n=44\end{array}$ \\
\hline $\begin{array}{c}\text { ETE } n=1 \\
\text { EETE } n=2 \\
\text { SFA } n=4\end{array}$ & $\begin{array}{l}\text { PBA } n=1 \\
\text { ETE } n=1 \\
\text { SFA } n=5\end{array}$ & & & $\begin{array}{l}\text { ETE } n=14 \\
\text { EETE } n=3 \\
\text { SFA } n=27\end{array}$ \\
\hline
\end{tabular}

Figure 1.2. Selection of patients for clinical study in connection with the method of treatment 


\subsection{Echocardiographic examination of the study patients}

Retrospective analysis of the preoperative and early postoperative transthoracic echocardiographic examinations of all $(n=74)$ the patients included in the study was carried out. Such parameters as the size of the aortic arch, the flow pattern and gradient in descending aorta, the size and function of the left ventricle, and concomitant intracardiac pathology were analyzed. Starting from 2008, prospective, repeated echocardiographic examination was carried out in all the surviving patients whose parents agreed to participate in the study $(n=59)$.

All the patients underwent standard M-mode, 2-dimensional and color doppler transthoracic echocardiography. The following projections were made to access the cardiac anatomy and function: subcostal long and short axis, apical, parasternal long and short axis, suprasternal views. The measurements of the aortic arch were carried out in the suprasternal long axis, sometimes using a modified high right parasternal view for newborn on the following levels: transverse arch (between the innominate and the left common carotid arteries), and isthmus (the narrowest segment distally from the left subclavian artery). The vessels were measured perpendicular to the long axis in a maximum expansion during systole.The measurements of the cardiovascular structures were expressed as z scores (Pettersen et al., 2008) using the Haycock formula to calculate the body surface area (BSA). The obstruction of the aortic arch was evaluated step by step using continuous wave dopplerography (CWD) from the proximal aortic arch to the proximal descending aorta. Recoarctation was defined as a blood pressure gradient between the upper and lower limb $\geq 20 \mathrm{~mm} \mathrm{Hg}$ or a peak instantaneous doppler gradient $\left(4 \mathrm{xV}_{\max }{ }^{2}\right)>25 \mathrm{~mm} \mathrm{Hg}$.

The echocardiographic protocol for the prospective measurements was supplemented by pulse wave dopplerographic (PWD) measurements in the 
abdominal aorta at the level of the diaphragm in the parasagital view (abdominal aorta in the long axis): maximum systolic velocity (PW S), minimum diastolic forward flow velocity (PW D), and the relation of PW maximum systolic to minimum diastolic flow (PW S/D) (Figure 1.3.).

The left ventricle dimensions were measured in M-mode from a parasternal long axis view at the level of the tips of the papillary muscles with the placement of an M-mode cursor guided by 2-dimensional imaging, and using the leading edge to leading edge technique. LVEDD - the left ventricle end diastolic dimension is defined as the beginning of the QRS complex, LVESD-left ventricle end systolic dimension, IVSd (ventricular septum in diastole), LVPWd (left ventricle posterior wall in diastole). FS (fractional shortening) measured in the M-mode short and long axis:

$$
\mathrm{FS}=(\text { LVEDD }- \text { LVEDS/LVEDD) }(1)(\text { normal values } 28-38 \%)
$$

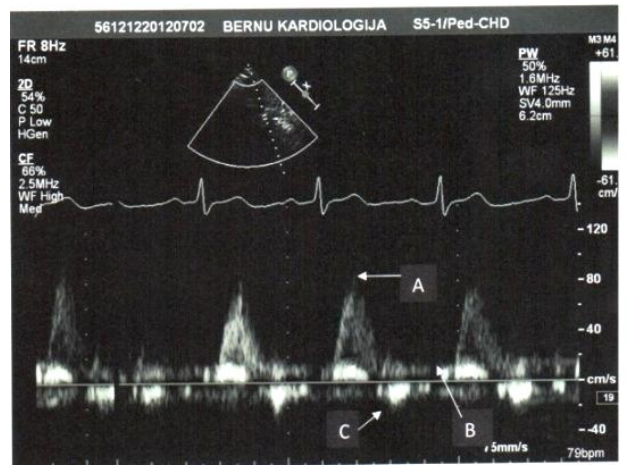

Figure 1.3. PWD flow pattern in abdominal aorta in a patient without recoarctation (A - maximum systolic forward flow, $B$ - minimum diastolic forward flow, C - early diastolic reversal)

The ejection fraction (EF) was measured in 2 dimensions:

$$
\mathrm{EF}=(\mathrm{EDV}-\mathrm{ESV} / \mathrm{EDV}) \times 100 \%
$$


The left ventricle mass (LVM) was calculated from M-mode measurements:

$$
\mathrm{LVM}=0.8\left(1.04\left([\mathrm{LVEDD}+\mathrm{LPWDd}+\mathrm{IVSd}]^{3}-[\mathrm{LVEDD}]^{3}\right)\right)+0.6 \mathrm{~g} \text { (3). }
$$

Left ventricle mass was indexed to height ${ }^{2.7}$ (Foster et al., 2008). The consistency of the results with the patients' weight, height and BSA was evaluated using normative charts. The echocardiographic data from the end of the study were compared to an age matched healthy control group (28 children, $n=17$ boys, $n=11$ girls), who did not differ from the study group according to gender $(p=0.55)$ and age $(p=0.69)$. The retrospective review of recordings made by Accuson Aspen and Hewlett Packard Sonos 4500 was carried out. Prospective echocardiographic examination was performed by Philips iE33 and HD11XE ultrasound systems using 2-dimensional (2D), pulse wave (PWD), continuous wave (CWD) doppler pediatric echocardiography programmes with a sectoral probe $3-5-8-12 \mathrm{MHz}$, and a sectoral probe $5-12 \mathrm{MHz}$ in neonates and small infants.

\subsection{Material and methods of the biomechanical study of the aortic arch}

The study was approved by the Ethics Commitee of the University Hospital for Children. During the period from April, 2009 to December 2011, 20 specimens ( $40 \mathrm{~mm}$ in lengh) of the upper part of the descending aorta were acquired during autopsies of neonates and infants (patients without a diagnosis of coarctation). The age of the patients was 1 day to 5 months (mean age $31.9 \pm 49.3$ days, median 6 days, $95 \%$ CI $6.7-58$ days) and the weight $2.0-6.7 \mathrm{~kg}$ (mean weight $3.9 \pm 1.3 \mathrm{~kg}$ ). The vessels were marked before resetting to identify 
the in situ axial lengh.The specimens were preserved in a Custadiol perfusion solution for not longer than 24 hours at a temperature of $2-4{ }^{\circ} \mathrm{C}$. A special experimental set up with a video camera connected to a laptop was used to measure the internal pressure, axial force, longitudinal and circumferential deformation of the aorta as in Figure 1.4. During the experiments, an aortic sample was gradually loaded by internal pressure from 0 to $220 \mathrm{~mm} \mathrm{Hg}$ while maintaining the length of the specimen $\mathrm{L}$ constant. The pressure was elevated in $20 \mathrm{~mm} \mathrm{Hg}$ steps with the pressure held constant in each step for 1 minute.

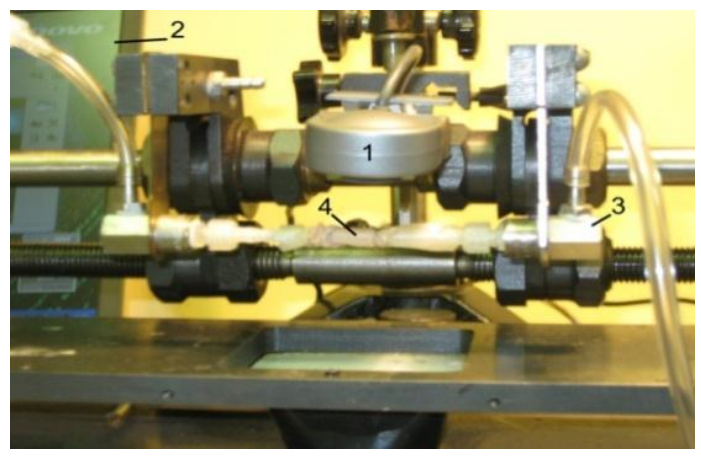

Figure 1.4. The common view of the experimental set-up: 1 - camera, 2 - computer, 3 - pressure transducer, 4 - specimen (aorta)

The initial external diameter at inner pressure $p=0 \mathrm{~mm} \mathrm{Hg}$ was noted as $D_{0}$. The diameter was measured at each pressure level. The value of wall thickness $h$ was calculated as follows:

$$
h=h_{\mathrm{O}} \times \lambda_{3}
$$

where

$$
\begin{aligned}
& \lambda_{3}=\frac{1}{\lambda_{1} \times \lambda_{2}} \\
& \lambda_{2}=\left(D / D_{O}\right)
\end{aligned}
$$


The circumferential stress was calculated as:

$$
\sigma=\frac{p R}{h}
$$

$\mathrm{P}$ - Inner pressure

$\mathrm{R}$ - radius

$$
\lambda_{1}=\left(\mathrm{L} / \mathrm{L}_{0}\right)=1,0
$$

In these equations, $h_{0}$ is the initial thickness of the specimen wall and $\lambda_{1}, \lambda_{2}$, and $\lambda_{3}$ are, respectively, the stretch ratios in the axial, circumferential and radial directions. Because the length of the artery was maintained constant at $L_{0}$, the value of $\lambda_{1}\left(=\mathrm{L} / L_{0}\right)$ was 1 . The initial wall thickness $h_{0}$ was measured with a cathetometer KM-6 with $\pm 0.001 \mathrm{~mm}$ accuracy. The artery was preconditioned before tests by subjecting it to cyclic loading to bring it to a stable state to give a more reproducible mechanical response. During this process, the vessel was pressurized from 0 to $200 \mathrm{~mm} \mathrm{Hg}$ in 20 steps, five times with the pressure held constant for 1 minute at each step. The initial curves were markedly hysteric, but the third or fourth cycle gave reproducible curves with minimum hysteresis. A modulus of elasticity $E$ was calculated as an incremental modulus between two values of internal pressure as in Figure 1.5. 


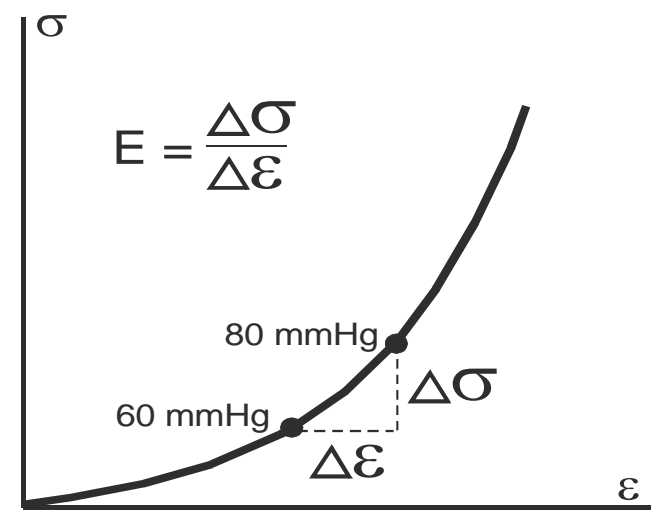

Figure 1.5. The calculation of the incremental modulus of elasticity-scematic picture

There were 20 specimens analysed: 10 specimens of native aorta, 3 specimens with anastomosis end-to-end (ETE), 4 specimens with extended anastomosis end-to-end (EETE), and 3 specimens with subclavian flap angioplasty (SFA). The anastomoses were made by the cardiac surgeon performing these kinds of operations in the clinic, using the suture techniques identical to the operation in vivo with uninterrupted sutures with Prolen 6.0-7.0 in the posterior and several interrupted sutures on the front wall of the descending aorta.

\subsection{Statistical analysis of the data}

The Microsoft Office Excel 2003 program was used for data storage and processing. A statistical SPSS 16.0 (SPSS Inc., Chicago, USA) was used for statistical analysis. Generally recognized statistical methods were used for the data processing. The ratio scale for variables was calculated by central tendency (arithmetic mean, median and mode) and dispersion (standard deviation 
and standard error of mean value) and percentages for the groups of categorical variables.

Advanced hypotheses, depending on the data structure, were tested by independent selection and selection t-test or single factor dispersion analysis (ANOVA). To determine a normal distribution of the data, the Kolmogorov`sSmirnov`s test was performed. Correlation and linear regression methods were used to find correlations between two or several variables. The closeness of correlations between the variables was estimated on the bases of the correlation coefficient value. A Pearson`s correlation coefficient was used as a measure of the strength of linear dependence between two variables and a Spearman`s correlation coefficient to measure the statistical dependence between two variables using a monotonic function. The correlation was estimated as poor, if $r=$ value was 0 up to 0.4 , as moderate, if the $\mathrm{r}$ value was estimated at 0.4 to 0.7 , and close, if $r$ reached 0.7 to 1.0 .

A Pearson`s chi-square test and Fisher`s exact tests were used to compare categorical variables of the groups. To evaluate the data, 95\% confidence intervals (CI) were calculated. A Kaplan-Meyer model was used to evaluate the survival function and the freedom from reinterventions. A significance level of $p<0.05$ was considered statistically significant for the evaluation of hypotheses. 


\section{RESULTS}

\subsection{The prevalence of coarctation of the aorta in neonates in Latvia between 2000-2010}

The prevalence of AoCo in neonates in Latvia between 2000-2010 was $3.4 \pm 1.3$ per 10000 live born infants. In the period from 2000-2004 it was $2.6 \pm 0.9$, but between $2005-2010$ it was $4.2 \pm 1.2$ per 10.000 live born infants $(p=0.094)$.

\subsection{Recognition of ductus dependent aortic coarctation in Latvia between 2005-2010}

There were 45 infants in the age group up to 2 months with AoCo treated at the University Hospital for Children from 1 January, 2005 to 31 December, 2010 (14 (31\%) were neonates and 31 (69\%) infants). The data shows that $64 \%$ $(n=29)$ of these patients were referred from the birth hospital (early diagnosis), while $36 \%(n=16)$ were sent after the discharge home by a general practitioner or by the emergency department of a regional hospital (late diagnosis). At the time of referral the diagnoses were AoCo or CHD with cardio-vascular insufficiency suspected in $73 \%(n=33)$ of the cases, but other diagnoses were suspected in $27 \%(n=12)$ of the cases (Figure 2.1.). Congenital heart dissease was suspected as a diagnosis for referral in $93 \%$ of early diagnosis, but only $38 \%$ in cases of late diagnoses (Fisher`s exact test, $p=0.0001$, Spearman`s $r=0.602, p=0.0001)$. Isolated AoCo were diagnosed later more often (52\%) than AoCo with concomitant intracardiac pathologies (18\%) (Fisher`s exact test, $p=0.029)$. Most cases of AoCo in combination with VSD $(77 \%, n=10)$ or 
complex coarctations $(89 \%, n=8)$ were transferred directly from the birth hospital. The infants with isolated AoCo constituted $75 \%(n=12)$ of the cases of late diagnosis $\left(\chi^{2}=6.0, \mathrm{df} 2, p=0.05\right)$.

\author{
- prolonged jaundice \\ - bronchiolitis, pneumonia \\ - genetic pathology suspected \\ - aspiration? \\ - feeding disturbances \\ - septicaemia? \\ - CHD or AoCo?
}

Figure 2.1. Referral diagnoses for neonates and infants with coarctation within the first 2 months of life between 2005-2010 $(n=45)$

The patient`s age at the time of diagnosis was $16.2 \pm 19.8$ days (minimum 1 , maximum 60 , mean 5), the patients age at the time of surgery was $23.5 \pm 19.8$ days (minimum 2, maximum 61, mean 13) and the weight $3.5 \pm 0.8 \mathrm{~kg}$ (minimum 2, maximum 5). The diagnosis was suspected antenatally in $27 \%$ $(n=12)$ of the cases. There were $51 \%(n=23)$ of patients with isolated AoCo, $29 \%(n=13)$ of patients with AoCo in combination with VSD, and 20\% ( $n=9)$ patients with complex coarctation (AoCo in combination with such intracardiac pathologies as mitral stenosis (MS), aortic stenosis, double outlet right ventricle (DORV) with VSD). There was a moderate correlation between concomitant intracardiac pathology and antenatal diagnosis (Spearman`s $r=0.407, p=0.006$, $n=45)$. PgE1 was used in $100 \%$ of the cases of the prenataly suspected AoCo and $48 \%$ of postnataly diagnosed cases. 
The differences between early and late diagnosis in the group with isolated AoCo are given in table 2.1. The infants with isolated AoCo and timely diagnosis were not in need of preoperative inotropic support and assisted ventilation and had normal acid-base parameters. Acidosis in capillary blood (Ph 7.18 \pm 0.04 ) was observed in $33 \%$ of the infants hospitalized after their discharge from the birth hospital. There was a case of early postoperative mortality in both groups. The cause of death in the early diagnosis group was septicaemia, but in the late diagnosis group, pneumonia and pulmonary hypertension. There were no cases of late death in this group.

There were 9 patients with complex AoCo and only one case of late diagnosis (AoCo in combination with supravalvular AoS). Most patients ( $n=8)$ were referred by the birth hospital and received PgE1. There was no need for inotropic support and ventilation prior to operation in their group.

There were 13 patients with AoCo in combination with VSD, with only 3 cases of late diagnosis observed. One of these patients was in need of inotropic support and had mild acidosis ( $P h$ 7.22) preoperatively. From the group of AoCo in combination with VSD and early diagnosis $(n=10)$, five of the patients received inotropic support and four were ventilated prior to operation. There was early postoperative death due to severe cardiovascular insufficiency observed in 3 cases of timely diagnosis.

A Cox regression analysis showed no connection between mortality within 30 days following the operation and the timing of the diagnosis $(p>0.05)$ in all of the groups. A late diagnosis influenced the preoperative condition in the group of isolated AoCo and the need for longer preoperative intensive care $(p=0.046)$. 
Table 2.1.

Comparison of patients with isolated AoCo transferred from the birth hospital and referred after discharge home (years 2005-2010)

\begin{tabular}{|l|c|c|c|}
\hline \multicolumn{1}{|c|}{ Factor } & $\begin{array}{c}\text { Early } \\
\text { diagnosis } \\
(\boldsymbol{n = 1 1 )}\end{array}$ & $\begin{array}{c}\text { Late diagnosis } \\
(\boldsymbol{n = 1 2})\end{array}$ & $\boldsymbol{P}$ value \\
\hline Acidosis in capillary blood & 0 & $4(33 \%)$ & $0.014^{1}$ \\
\hline Preoperative inotropic support & 0 & $3(25 \%)$ & $0.038^{1}$ \\
\hline Preoperative assisted ventilation & 0 & $3(25 \%)$ & $0.038^{1}$ \\
\hline $\begin{array}{l}\text { Time from admission to } \\
\text { operation (days) }\end{array}$ & $4.6 \pm 2.2$ & $7.3 \pm 3.5$ & $0.046^{2}$ \\
\hline $\begin{array}{l}\text { Age at the time of diagnosis } \\
\text { (days) }\end{array}$ & $8.7 \pm 16.9$ & $32.1 \pm 15.6$ & $0.003^{2}$ \\
\hline $\begin{array}{l}\text { Weight at the time of operation } \\
\text { (kg) }\end{array}$ & $3.3 \pm 0.6$ & $4.1 \pm 0.6$ & $0.004^{2}$ \\
\hline Early mortality & 1 & 1 & $\mathrm{NS}^{*}$ \\
\hline
\end{tabular}

${ }^{1}$ Likelihood $\chi^{2}$

${ }^{2}$ t-test

* not significant

\subsection{The results of surgical correction of coarctation in infants in Latvia between 2000-2010}

During the period from 1 January, 2000 to 31 December, 2010, 74 infants underwent correction of coarctation of the aorta within the first year of life at the University Hospital for Children, Riga (44 boys (59\%), 30 girls (41\%) (Figure 2.2.). The mean age of the patients at the time of surgery was $47.3 \pm 58$ days (minimum - 2, maximum - 243, median - 24 days), between 2000-2004 68.7 \pm 67.3 days (median - 51 day), but between 2005-2010 37.7 \pm 51.6 days (median -20 days) $(p=0.033)$. The patients' weights at the time of surgery were 
$4.2 \pm 1.6 \mathrm{~kg}$. The indications for surgical repair of AoCo were conservatively untreatable cardio-vascular insufficiency.

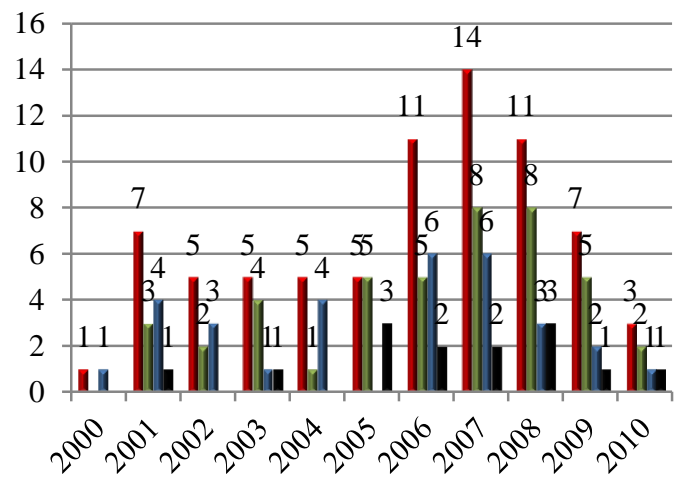

AoCo within the first year of life

aNeonates

国Infants

Died during the study period

Figure 2.2. The results of surgical correction of coarctation of the aorta in neonates and infants between 2000-2010 in Latvia

The diagnosis was suspected antenatally in $19 \%$ of the cases (in $4 \%$ of the cases between 2000-2004 and 25\% of the cases between 2005-2010, $\chi^{2}=4,62$, df1, $p=0.032$ ). There was a need for preoperative inotropic support in $20 \%$ of the cases and assisted ventilation in $18 \%$ of the cases. The necessity for intensive preoperative care was not statistically different between 2000-2004 and 2005-2010. Inotropic preoperative support was used in 6 of 23 patients between 2000-2004, but in 9 of 51 patients between 2005-2010 ( $\chi^{2}=0,69$, df1, $p=0,403$, Fisher`s exact test $p=0,533)$, preoperative assisted ventilation was used for 6 of 23 patients between 2000-2004, but 7 of 51 patient between 2005$2010\left(\chi^{2}=1,673\right.$, df1, $p=0,196$, Fisher`s exact test $\left.p=0,206\right)$.

According to the anatomy of the CHD, the patients were made up of the following: group-I (simple AoCo with or without ASD) 57\%, group-II: patients with AoCo and VSD 23\%, group-III: complex coarctation 20\% (Table 2.2.). 
Infantile juxtaductal AoCo with hypoplasia of the isthmus was observed in $83 \%(n=62)$ of the cases, postductal AoCo in $4 \%(n=3)$ of the cases and juxtaductal membrane in 12\% ( $n=9)$ of the cases. Hypoplasia of the aortic arch (transverse aortic arch below $-2 z$ score value according to the patient's body surface area) was observed in 16.

The techniques for the primary repair of AoCo included resection with anastomosis end-to end (ETE) in 26\% $(n=19)$ of the cases, subclavian flap aortoplasty (SFA) in 65\% ( $n=48)$ of the cases, extended anastomosis end-to-end (EETE) in $8 \%(n=6)$ of the cases while one patient underwent primary balloon angioplasty (PBA).

There were 7 cases of early postoperative mortality within 30 days following the operation (9\%) (the causes of the death: 1 case of septicaemia, 4 cases of severe cardio-vascular insufficiency, 1 case of acute renal failure (peritoneal dialysis), 1 case of pneumonia and pulmonary hypertension).

There were 7 cases of late death further in the study period. The causes of death were: 2 cases of endocardial fibroelastosis, 2 death outside the hospital (no autopsy data), 1 case of bilateral pneumonia, 1 case of severe metabolic acidosis and septicaemia suspected (autopsy not performed), 1 patient died at the age of 3.5 months during the correction of severe complex intracardiac pathology.

There were no cases of lower paraplegia in the study group, but one patient developed left sided haemiparesis during the postoperative period. The survival of the patients is characterized by a Kaplan-Meyer survival curve (Figure 2.3.), but survival in the study period in connection with the concomitant intracardiac pathologies is shown in the Figure 2.4. 
Table 2.2.

The groups of patients with coarctation according to the concomitant intracardiac pathology within the first year of life between 2000-2010 $(n=74)$

\begin{tabular}{|c|c|c|}
\hline Patients & Concomitant intracardiac pathology & $\begin{array}{c}\text { Number of } \\
\text { patients }\end{array}$ \\
\hline Group I & No (simple AoCo) \pm ASD & $42(57 \%)$ \\
\hline Group II & $\mathrm{AoCo}+\mathrm{VSD}$ & $17(23 \%)$ \\
\hline \multirow{10}{*}{$\begin{array}{c}\text { Group } \\
\text { III }\end{array}$} & Complex AoCo: & $15(20 \%):$ \\
\hline & - DORV+VSD & 1 \\
\hline & - Subvalvular AoS+VSD & 1 \\
\hline & - Subvalvular AoS & 4 \\
\hline & - Valvular AoS & 4 \\
\hline & - Supravalvular AoS & 1 \\
\hline & - Mitral insufficiency (valvular pathology) & 1 \\
\hline & - Mitral stenosis+VSD & 1 \\
\hline & - Atrio-ventricular septal defect & 1 \\
\hline & - Pulmonary stenosis+ASD & 1 \\
\hline
\end{tabular}

Of the study group, $81.1 \%$ of patients were alive at the end of the study (95\% CI cumulative survival 99.3-123.5 months) (Figure 2.3.). An analysis of the groups of patients in connection with concomitant intracardiac pathology showed: cumulative survival of the patients with simple AoCo 95\% (95\% CI 121.8-139.3 months), AoCo in combination with VSD 59\% (95\% CI 35.0-79.9 months), complex AoCo 67\% (95\% CI 52.7-108.9 months) ( $p=0.001$ ) (Figure 2.4.).

The cumulative survival was not statistically different in the cases of different surgical methods used: ETE 89.5\% (95\% CI 104.1-141.4 months), 
SFA $81 \%$ (95\% CI 84.7-111.6 months), EETE $67 \%$ (95\% CI $38.1-135.7$ months) $(p=0.371)$.

There were more cases with the diagnosis detected prenatally within the group of lethal cases which are connected with concomitant intracardiac pathologies $\left(\chi^{2}=6.45\right.$, df1, $\left.p=0.01\right)$, more cases of preoperative inotropic support $\left(\chi^{2}=5.45, \mathrm{df} 1, p=0.02\right)$ and preoperative assisted ventilation $\left(\chi^{2}=7.63\right.$, df1, $p=0.006$ ), and there were more patients with a hypoplastic aortic arch (Fisher`s exact test $p=0.0001$ ).

\section{Survival Function}

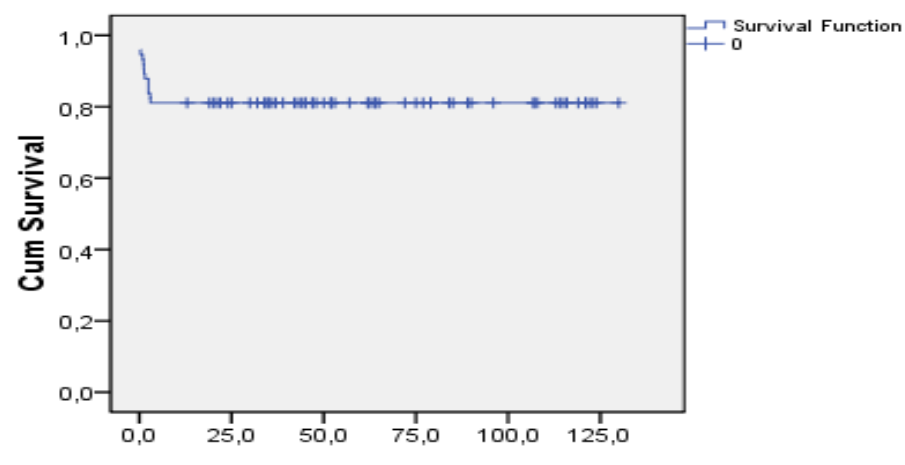

Aqe in months

Figure 2.3. Cumulative survival of neonates and infants with aortic coarctation in the study group $(n=74)$

There was a moderate correlation between concomitant intracardiac pathology and death within the study period observed (Spearrman`s $r=0.402$, $n=74, p=0.0001$ ). 


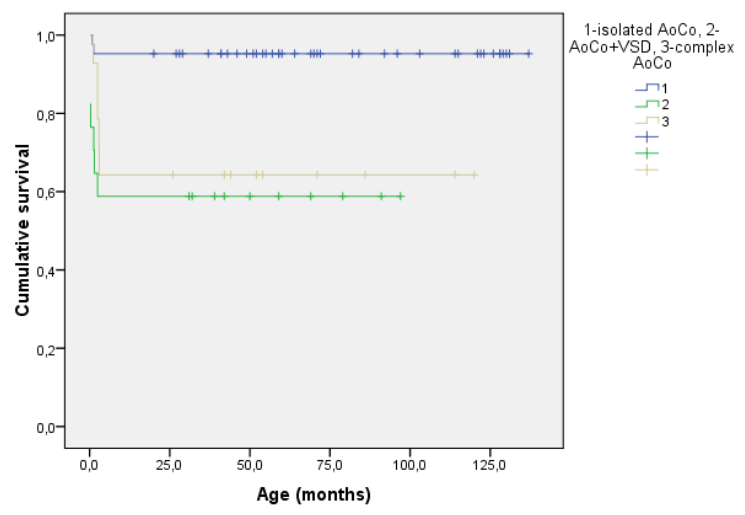

Figure 2.4. Cumulative survival of neonates and infants with coarctation in connection with concomitant intracardiac pathology $(n=74)$ 1 - simple AoCo, 2 - AoCo+VSD, 3 - complex AoCo

There were 15 cases of recoarctation of the aorta during the study period (the gradient in descending aorta $>25 \mathrm{~mm} \mathrm{Hg}$ with luminal narrowing $\geq 50 \%$ and hypertension on the upper extremities) (25\% of the cases, excluding the lethal cases) at the age from 2 months to 8 years and $73 \%$ of these patients had undergone surgical correction of AoCo as neonates. $60 \%$ of the cases of recoarctation were observed within the first year following the primary correction. There were no statistically significant differences between the incidence of recoarctation depending on the method of primary surgical correction: $18 \%$ in the ETE group, $29 \%$ in the SFA group and $25 \%$ in the EETE group, $p=0.67$ ) (Figure 2.5.).

All of the patients underwent balloon angioplasty of recoarctation at the age of $35.7 \pm 33$ months ( 2 months -8 years). Follow up of the patients lasting $70.7 \pm 33.4$ months was carried out (minimum 18 months, maximum 131 months), the patients`ages at the end of the study were 1 year 6 months -11 years 3 months (73.2 \pm 34.4 months, 95\% CI 64.2-82.1 months). 
4 of 59 patients $(7 \%)$ were receiving antihypertensive treatment without a significant residual gradient at the end of the study, 5 patients from the study group had their arterial pressure at the $90^{\text {th }}$ percentile, with 1 at $95^{\text {th }}$ percentile (prehypertension /hypertension in $10 \%$ of the cases), though other patients had their arterial pressure up to the $75^{\text {th }}$ percentile. None of the patients developed aortic aneurysm within the study period.

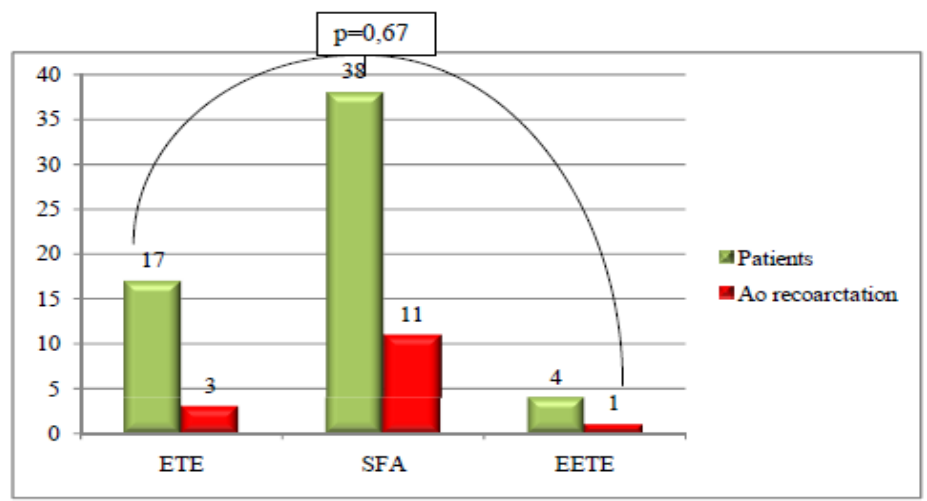

Figure 2.5. Recoarctation of the aorta in connection with the surgical technique of primary correction

Measurements of the arms and forearms were bilaterally carried out in patients who had undergone surgical correction of coarctation using subclavian flap aortoplasty $(n=34,89 \%)$. The patients`ages at the time of measurement were $4.7 \pm 2$ years. The lengh of the right upper arm was $21.32 \pm 3.6 \mathrm{~cm}$, but the left upper arm $21.22 \pm 3.7 \mathrm{~cm}(p=0.92)$, the lengh of the right forearm was $16.08 \pm 2.59 \mathrm{~cm}$, but the left forearm $15.97 \pm 2.61 \mathrm{~cm}(p=0.86)$. There was a shortening of the left upper extremity observed in 4 patients, the left upper arm was $0.5-1.0 \mathrm{~cm}$ shorter, but the forearm $0.5-0.7 \mathrm{~cm}$ shorter than the right one, and there was an asymmetry of the palms observed in 1 patient (the left slightly 
smaller than the right one). There were differences in the arms observed in $14.7 \%$ of the patients' following SFA as a result of subclavian steal; however the patients and their parents did not mention functional disturbances.

\subsection{Echocardiographic study of patients following surgical correction of aortic coarctation within the first year of life}

There was a medium long-term echocardiographic follow-up carried out in 35 boys (59\%) and 24 girls (41\%) who were operated on as neonates in $46 \%$ $(n=27)$ of the cases, but as infants in $54 \%(n=32)$ of the cases. The methods of surgical correction were ETE in 29\% ( $n=17)$, EETE in $7 \%(n=4)$ and SFA in $64 \%(n=38)$. The characteristics of the patients at the time of primary correction are given in Table 2.3.

The CW doppler gradient (CW Pg max.) in descending Ao was $62 \pm 23$ $\mathrm{mm} \mathrm{Hg}$ prior to the surgery. The LVEDD was $20.9 \pm 5.6 \mathrm{~mm}$; IVSd was $6.2 \pm 1.7$ $\mathrm{mm}$ and LVPWd $4.8 \pm 1.2 \mathrm{~mm}$. 21 of 59 pacients (36\%) had concomitant intracardiac pathologies (Table 2.4.). Only 7 patients (12\%) had a bicuspid Ao valve.

The left ventricle mass (LVM) prior to surgery was $22.9 \pm 13.8 \mathrm{~g}$ (measured in patients without AoS, MS, PS, $n=49$ ). The size of the transverse aortic arch was $7.1 \pm 1.4 \mathrm{~mm}(95 \%$ CI 6.7-7.5 mm). There were 8 cases (13\%) of hypoplastic transverse $\operatorname{arch}(z$ value $\leq-2)$ (Figure 2.6.). The diameter of coarctation site was $2.5 \pm 0.7 \mathrm{~mm}$. 
Table 2.3.

Characteristics of the patients at the time of primary surgical correction of AoCo $(n=59)$

\begin{tabular}{|c|c|c|c|c|}
\hline \multirow{2}{*}{ Parameter } & \multirow{2}{*}{ Mean } & \multirow{2}{*}{$\begin{array}{l}\text { Standard } \\
\text { deviation }\end{array}$} & \multicolumn{2}{|c|}{$95 \%$ CI } \\
\hline & & & Minimum & Maximum \\
\hline $\begin{array}{l}\text { Age at the time of } \\
\text { surgery (days) }\end{array}$ & 55.37 & \pm 61.34 & 2 & 243 \\
\hline Weight (kg) & 4.41 & \pm 1.74 & 1.7 & 9.6 \\
\hline Height $(\mathrm{cm})$ & 55.75 & \pm 6.40 & 45 & 76 \\
\hline $\begin{array}{l}\text { Body surface area } \\
\qquad\left(\mathrm{m}^{2}\right)\end{array}$ & 0.26 & \pm 0.07 & 0.15 & 0.46 \\
\hline
\end{tabular}

The patients with AoCo and VSD had smaller transverse arches than those with isolated AoCo $(6.2 \pm 1.5 \mathrm{~mm}$ versus $7.4 \pm 1.3 \mathrm{~mm}, p=0.015)$. The transverse arch in the patients who had undergone ETE was $7.9 \pm 1.5 \mathrm{~mm}$, in the cases of SFA $6.8 \pm 1.3 \mathrm{~mm}(p=0.007$, ETE versus SFA), and $6.5 \pm 1.3 \mathrm{~mm}$ in the cases of EETE ( $p=0.66$, SFA versus EETE). Prior to surgery $17 \%(n=10)$ of the patients had decreased left ventricle systolic function with an ejection fraction (EF) below 55\%. Following the operation the CWD Pg max. in the descending aorta was $18.6 \pm 9 \mathrm{~mm} \mathrm{Hg}$, none of the patients had significant residual gradient. Only one patient had decreased left ventricle EF. 
Table 2.4.

Concomitant intracardiac pathologies in the patients $(n=59)$ followed up

\begin{tabular}{|c|c|}
\hline Concomitant intracardiac pathology & Count (\% of all 59 patients) \\
\hline $\begin{array}{c}\text { Ventricular septal defect (VSD): } \\
\text { Perimembranous VSD } \\
\text { Muscular VSD }\end{array}$ & $10(17 \%)$ \\
7 \\
Atrial septal defect (significant) & $1(2 \%)$ \\
\hline Aortic stenosis (AoS) & $\begin{array}{c}\text { Valvular AoS } \\
\text { Subvalvular AoS }\end{array}$ \\
Supravalvular AoS & 3 \\
1 \\
\hline Pulmonary stenosis (PS)+ASD & $1(2 \%)$ \\
\hline Mitral valve pathology & $1(2 \%)$ \\
\hline Mitral stenosis (MS)+VSD & $1(2 \%)$ \\
\hline
\end{tabular}

The patients were followed up for $70.4 \pm 33.4$ months ( 1 year 6 months to 11 years). During the study period 10 patients were in need of surgical repair of concomitant intracardiac pathology at the age of $21 \pm 13.5$ months (freedom from the need for intracardiac repair 84.7\% (95\% CI 107.5-129.7 months). 


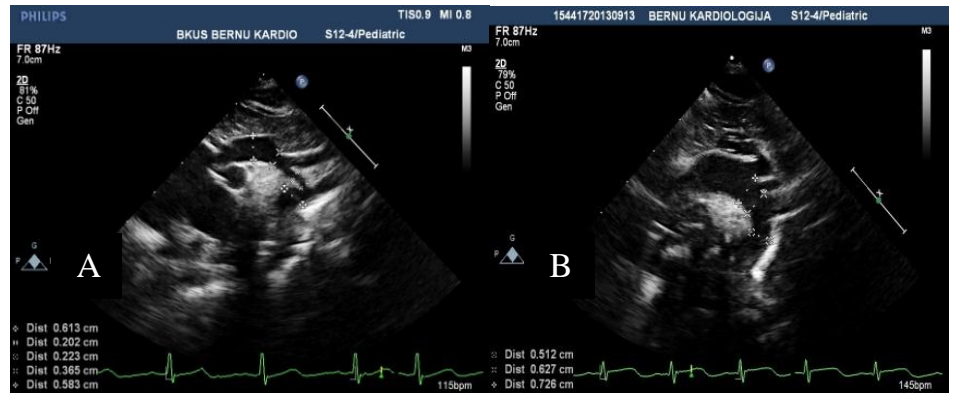

Figure 2.6. A - AoCo with hypoplastic Ao arch in neonate, B - normal Ao arch in neonate

Balloon angioplasty of Ao recoarctation was commenced at the University Hospital for Children on January, 2009. There was recoarctation observed in 15 patients $(25 \%)$ in the study group. The cumulative survival without recoarctation during the study period was $74.6 \%$ (95\% CI 89.6-118.1 months) (Figure 2.7.).

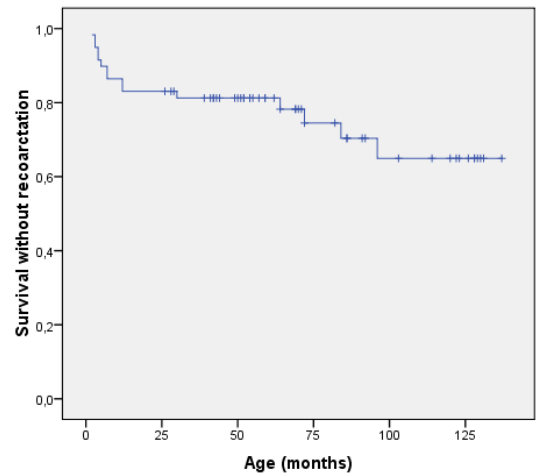

Figure 2.7. Cumulative survival without recoarctation during the study period 
The patients`ages at the time of angioplasty were $35.7 \pm 33.7$ months (2 months to 8 years). Before the balloon angioplasty CWD Pg max.in descending Ao was $78 \pm 19 \mathrm{~mm} \mathrm{Hg}$ with a diastolic foreard flow (Figure 2.8.).

The echocardiographic findings at the time of recoarctation and the end of the follow-up period in comparison with an age matched healthy control group are given in table 2.5 .

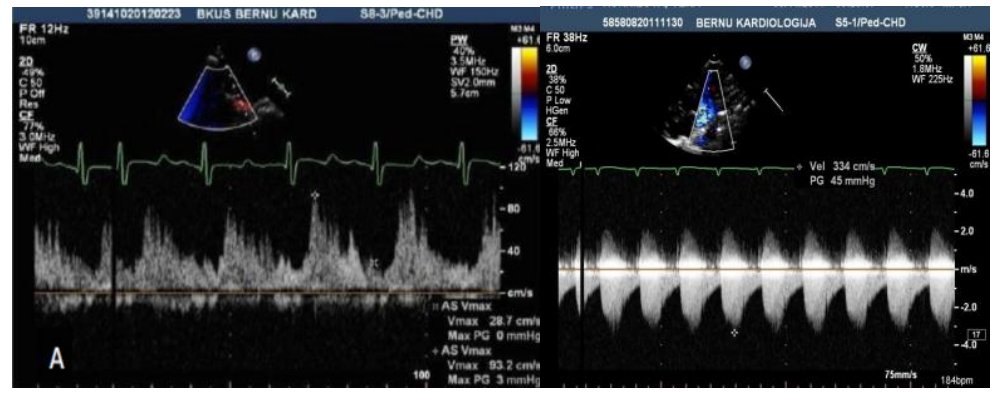

Figure 2.8. A 3 months old infant with Ao recoarctation: A - PWD flow pattern in abdominal Ao-PWD S/D 3,2; B - CWD flow in descending Ao (high gradient with diastolic forward flow)

At the end of the study, the patients` CWD Pg max. in descending Ao was $20 \pm 8.9 \mathrm{~mm} \mathrm{Hg}$ (95\% CI 17.6-22.4 mm Hg), and no patient was in need of current reintervention. The $\mathrm{LVMi} /$ height $^{2,7}$ for the study patients was $42.49 \pm 7.07$, median 42.25 (95\% CI 40.39-44.59), while in the control group it was $39.47 \pm 7.04$ median 40.35 (95\% CI 36.74-42.20), but for the patients with a recoarctation prior balloon angioplasty $76.32 \pm 19.88$, median 71.70 (95\% CI 65.31-87.33) (Figure 2.9.). At the end of the study period the left ventricle mass index remained higher for the patients following recoarctation $\left(45.67 \pm 6.53 \mathrm{~g} / \mathrm{m}^{2,7}\right) \quad$ versus the patients without recoarctation $\left(41.63 \pm 6.56 \mathrm{~g} / \mathrm{m}^{2,7}\right)$ and the control group $\left(39.47 \pm 7.04 \mathrm{~g} / \mathrm{m}^{2,7}\right), \quad(p=0.019)$. However there were no significant differences in LVMi $z$ values $(p=0.087)$ (Foster et al., 2008). 

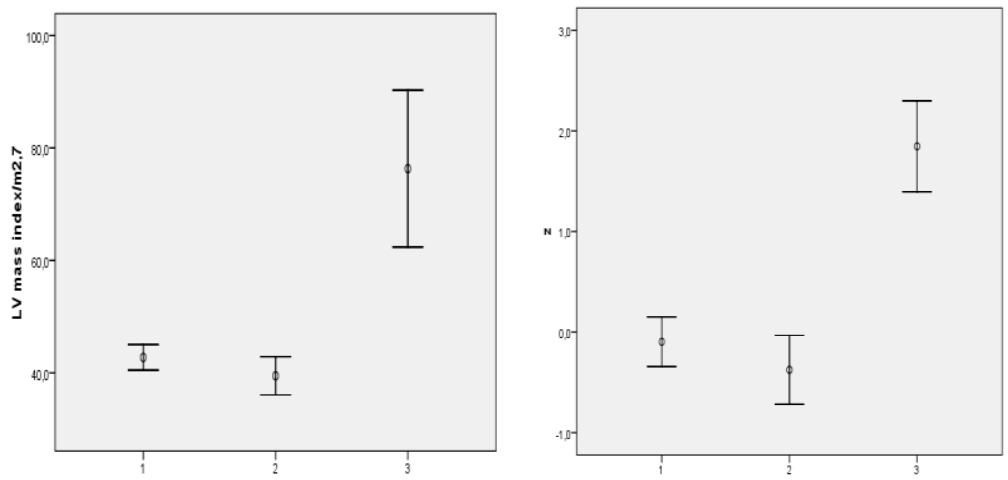

Figure 2.9. A comparison of left ventricle mass index and left ventricle mass $z$ values ( 1 - patients at the end of the study, 2 - control group, 3 - patients before ballon angioplasty of recoarctation)

The period of time from the balloon angioplasty and the end of the study was $21.1 \pm 8.3$ months. The Ao transverse arch in the study group was $12.43 \pm 1.8 \mathrm{~mm}$, and $13.36 \pm 1.98 \mathrm{~mm}$ in the control group $(p=0.029 \mathrm{~mm})$, Ao transverse $\operatorname{arch} z$ value in the study group was $-0.93 \pm 0.74$ and $-0.69 \pm 0.55$ in the control group ( $p=0.137)$. There were no significant differecnces between the Ao transverse arch sizes between the methods of correction: anastomosis ETE $12.38 \pm 2.34 \mathrm{~mm}$, SFA $12.35 \pm 1.68 \mathrm{~mm}$ and EETE $13.25 \pm 1.26 \mathrm{~mm}(p=0.652)$. The size of the Ao isthmus in the study group was $9.31 \pm 1.55 \mathrm{~mm}$, but in the control group $11.45 \pm 2.06 \mathrm{~mm}$ ( $p=0.0001$ ). The Ao isthmus $z$ value for the study group patients was $-0.74 \pm 0.76$ versus $-0.01 \pm 0.67$ for the control group $(p=0.0001)$. 
Table 2.5.

\section{Comparison of LVM, LVMi and PWD dopplerographic findings between} the study group at the time of recoarctation, the end of the study, and the control group

\begin{tabular}{|c|c|c|c|c|}
\hline Parameters & $\begin{array}{c}\text { Patients at } \\
\text { the end of } \\
\text { the study } \\
\text { period } \\
(\boldsymbol{n}=\mathbf{5 9})\end{array}$ & $\begin{array}{c}\text { Patients } \\
\text { prior to } \\
\text { ballon } \\
\text { angioplasty } \\
\text { of } \\
\text { recoarctation } \\
(\boldsymbol{n}=\mathbf{1 5})\end{array}$ & $\begin{array}{c}\text { Control } \\
\text { group } \\
(\boldsymbol{n}=\mathbf{2 8})\end{array}$ & $\boldsymbol{P}$ value \\
\hline Age (months) & $73.17 \pm 34$ & $35.67 \pm 33$ & $69.96 \pm 36$ & $* 0.69, * * 0.005$ \\
\hline LVM (g) & $57.76 \pm 21$ & $63.11 \pm 36$ & $61.34 \pm 25$ & $\begin{array}{c}* 0.51, * * 0.85, \\
* * * 0.48\end{array}$ \\
\hline LVM $z$ value & $-0.09 \pm 0.7$ & $1.85 \pm 0.64$ & $-0.37 \pm 0.71$ & $\begin{array}{c}* * 0.0001, \\
* * * 0.0001\end{array}$ \\
\hline $\begin{array}{c}\text { LVMi/height } \\
\text { 1 }\end{array}$ & $42.49 \pm 7.06$ & $76.32 \pm 19$ & $39.47 \pm 7.04$ & $\begin{array}{c}* * 0.078, \\
* * 0.0001, \\
* * 0.0001\end{array}$ \\
\hline PWD S Ao \\
$(\mathrm{m} / \mathrm{s})$
\end{tabular}

* Comparison between the control group and patients at the end of the study ( $t$-test)

** Comparison between the control group and patients with recoarctation prior to balloon angioplasty ( $t$-test)

*** Comparison between patients at the end of the study and patients with recoarctation prior to balloon angioplasty (t-test)

${ }^{1}$ LVM, LVM z values, LVMi/height ${ }^{2,7}$ in the study group calculated for the patients without AoS and MV pathology $(n=49)$ 


\subsection{The biomechanical properties of different modalities of surgically corrected aorta in neonates and infants}

The biomechanical experiments showed a non-linear relationship between stress and strain in neonatal and infantile aorta (Figure 2.10.).

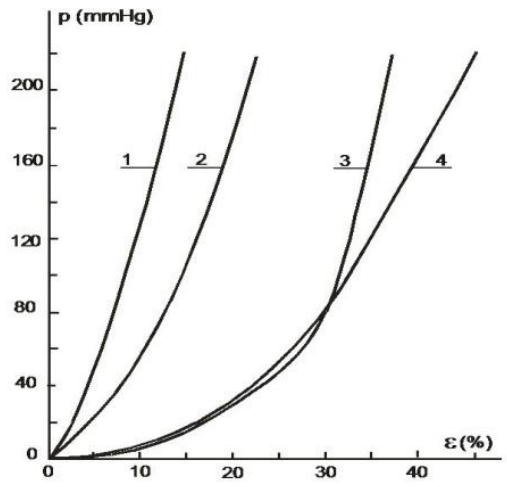

Figure 2.10. The relationship between pressure and strain: 1 - anastomosis end-toend (ETE), 2 - extended anastomosis end-to-end (EETE),

3 - subclavian flap aortoplasty (SFA), 4 - native aorta

The wall thickness of the samples was $1.1 \pm 0.1 \mathrm{~mm}$ (minimum $0.91 \mathrm{~mm}$, maximum $1.26 \mathrm{~mm}$, median $1.125 \mathrm{~mm}$, mode $1.06 \mathrm{~mm}$ ). The strain of the aorta at an inner pressure of $60 \mathrm{~mm} \mathrm{Hg}$ was $25.12 \pm 9.37 \%$, at $80 \mathrm{~mm} \mathrm{Hg}$ it was $29.37 \pm 11.62 \%$, at $100 \mathrm{~mm} \mathrm{Hg} 32.62 \pm 13.37 \%$ (Table 2.6.). The maximum strain at an inner pressure of $220 \mathrm{~mm} \mathrm{Hg}$ was $47.65 \pm 15.41 \%$. The stress of the native aorta at an inner pressure of $60 \mathrm{~mm} \mathrm{Hg}$ was $45.32 \pm 15.29 \mathrm{kPa}$, at $80 \mathrm{~mm}$ $\mathrm{Hg}$ it was $65.36 \pm 24.2 \mathrm{kPa}$, at $100 \mathrm{~mm} \mathrm{Hg} 86.31 \pm 33.54 \mathrm{kPa}$, but at $220 \mathrm{~mm}$ $\mathrm{Hg}-253.41 \pm 95.94 \mathrm{kPa}$ (Table 2.7.). The level of significance $p$ of the differences between samples is given in tables 2.8. and 2.9. 
Table 2.6.

The strain in the wall of the native aorta, ETE, SFA, EETE at different levels of inner pressure

\begin{tabular}{|c|c|c|c|c|}
\hline Specimen & $\begin{array}{c}\boldsymbol{\varepsilon}(\boldsymbol{\%}) \\
\mathbf{6 0} \mathbf{~ m m} \mathbf{H g}\end{array}$ & $\begin{array}{c}\boldsymbol{\varepsilon}(\boldsymbol{\%}) \\
\mathbf{8 0} \mathbf{~ m m} \mathbf{H g}\end{array}$ & $\begin{array}{c}\boldsymbol{\varepsilon}(\boldsymbol{\%}) \\
\mathbf{1 0 0} \mathbf{~ m m ~} \mathbf{H g}\end{array}$ & $\begin{array}{c}\boldsymbol{\varepsilon}(\boldsymbol{\%}) \\
\mathbf{1 2 0} \mathbf{~ m m ~} \mathbf{H g}\end{array}$ \\
\hline Native Ao & $25.12 \pm 9.37$ & $29.37 \pm 11.62$ & $32.62 \pm 13.37$ & $34.93 \pm 14.43$ \\
\hline SFA & $26.41 \pm 67.25$ & $28.87 \pm 6.29$ & $30.62 \pm 6.26$ & $31.91 \pm 6.2$ \\
\hline EETE & $10.01 \pm 1.59$ & $12.25 \pm 1.73$ & $14.06 \pm 2.05$ & $15.77 \pm 2.38$ \\
\hline ETE & $4.83 \pm 1.22$ & $6.33 \pm 1.29$ & $7.63 \pm 1.22$ & $8.9 \pm 1.40$ \\
\hline
\end{tabular}

In the cases with anastomosis end-to-end (ETE), the relationship between stress and strain was practically linear (Figure 2.9.). The srain in ETE decreased and and at an inner pressure of $60 \mathrm{~mm} \mathrm{Hg}$ it was $4.83 \pm 1.22 \%$, at $80 \mathrm{~mm} \mathrm{Hg}$ was $6.33 \pm 1.29 \%$ and at $100 \mathrm{~mm} \mathrm{Hg} 7.63 \pm 1.22 \%$. The maximum strain at the suture site at an inner pressure $220 \mathrm{~mm} \mathrm{Hg}$ reached only $15.78 \pm 3.09 \%$. Comparing the strain of native aorta with anastomoses, we came to the conclusion that the strain of the anastomosis ETE was much smaller but at an inner pressure $220 \mathrm{~mm} \mathrm{Hg}$ it was half as much as the native aorta. In cases of a subclavian flap aortoplasty (SFA) the strain at an inner pressure of $60 \mathrm{~mm}$ $\mathrm{Hg}$ was $26.41 \pm 67.25 \%$, at $80 \mathrm{~mm} \mathrm{Hg}$ was $28.87 \pm 6.29 \%$, but at $100 \mathrm{~mm} \mathrm{Hg}$ was $30.62 \pm 6.26 \%$. The maximum strain at an inner pressure of $220 \mathrm{~mm} \mathrm{Hg}$ reached $37.73 \pm 7.86 \%$, which is the closest to the strain of the native. In the cases of extended anastomosis end-to-end (EETE) the strain at inner pressure $60 \mathrm{~mm} \mathrm{Hg}$ was $10.01 \pm 1.59 \%$, at $80 \mathrm{~mm} \mathrm{Hg}$ was $12.25 \pm 1.73 \%$, and at $100 \mathrm{~mm} \mathrm{Hg}$ it was $14.06 \pm 2.05 \%$. Maximum strain at inner pressure $220 \mathrm{~mm} \mathrm{Hg}$ reached $22.57 \pm 2.85 \%$, which exceeds the strain in the cases of ETE twice, but drops back in comparison with SFA and native aorta. 
Table 2.7.

The stress in the wall of native aorta, ETE, EETE and SFA at different levels of inner pressure

\begin{tabular}{|c|c|c|c|c|}
\hline Specimen & $\begin{array}{c}\boldsymbol{\sigma}(\mathbf{k P a}) \\
\mathbf{6 0} \mathbf{~ m m} \mathbf{~ H g}\end{array}$ & $\begin{array}{c}\boldsymbol{\sigma}(\mathbf{k P a}) \\
\mathbf{8 0} \mathbf{~ m m ~ H g}\end{array}$ & $\begin{array}{c}\boldsymbol{\sigma}(\mathbf{k P a}) \\
\mathbf{1 0 0} \mathbf{~ m m ~ H g}\end{array}$ & $\begin{array}{c}\boldsymbol{\sigma}(\mathbf{k P a}) \\
\mathbf{1 2 0} \mathbf{~ m m} \mathbf{H g}\end{array}$ \\
\hline $\begin{array}{c}\text { Native } \\
\text { Ao }\end{array}$ & $45.32 \pm 15.29$ & $65.36 \pm 24.2$ & $86.31 \pm 33.54$ & $108.04 \pm 42.72$ \\
\hline SFA & $35.99 \pm 7.58$ & $51.10 \pm 1.79$ & $65.09 \pm 2.91$ & $78.35 \pm 6.81$ \\
\hline EETE & $39.32 \pm 3.49$ & $54.44 \pm 4.74$ & $70.11 \pm 6.28$ & $86.66 \pm 7.93$ \\
\hline ETE & $36.15 \pm 2.85$ & $49.52 \pm 4.01$ & $63.41 \pm 7.28$ & $78.35 \pm 6.81$ \\
\hline
\end{tabular}

The modulus of elasticity of the wall of the native aorta increased with an increase in the inner pressure (Table 2.8.). At an inner pressure of $60-80 \mathrm{~mm}$ $\mathrm{Hg}$ the modulus of elasticity was $516.08 \pm 126.21 \mathrm{kPa}$, but at $100-120 \mathrm{~mm} \mathrm{Hg}$ it increased up to $967.45 \pm 164.60 \mathrm{kPa}$ (more than twice).

In the ETE, the modulus of elasticity was almost constant and at a pressure of $60-80 \mathrm{~mm} \mathrm{Hg}$ it was $1138.08 \pm 216.23 \mathrm{kPa}$, but at a pressure of 100$120 \mathrm{~mm} \mathrm{Hg}$ the modulus of elasticity increased up to $1261.35 \pm 235.76 \mathrm{kPa}$.

The modulus of elasticity at an inner pressure of $60-80 \mathrm{~mm} \mathrm{Hg}$ was closer to the modulus of elasticity of the native aorta at an inner pressure of 100-120 $\mathrm{mm} \mathrm{Hg}$. The results showed that in cases of ETE, stiffness does not practically change with changes of inner pressure that might affect the hemodynamics. In the cases of EETE, the modulus of elasticity at an inner pressure of $60-80 \mathrm{~mm}$ $\mathrm{Hg}$ was $683.29 \pm 65.87 \mathrm{kPa}$, but at $100-120 \mathrm{~mm} \mathrm{Hg}$ it was $1232.79 \pm 586.79 \mathrm{kPa}$. In cases of SFA, the modulus of elasticity at an inner pressure of $60-80 \mathrm{~mm} \mathrm{Hg}$ was $615.95 \pm 50.88 \mathrm{kPa}$, but at a pressure of $100-120 \mathrm{~mm} \mathrm{Hg}$, it was $1158.35 \pm 127.52 \mathrm{kPa}$, which is closer to the modulus of elasticity of the native aorta. 
Table 2.8.

The modulus of elasticity of the wall of the native aorta, ETE, EETE and SFA anastomoses at different levels of inner pressure

\begin{tabular}{|c|c|c|c|}
\hline Specimen & $\begin{array}{c}\mathbf{E}(\mathbf{k P a}) \\
\mathbf{6 0 - 8 0} \mathbf{~ m m} \mathbf{H g}\end{array}$ & $\begin{array}{c}\mathbf{E}(\mathbf{k P a}) \\
\mathbf{8 0 - 1 0 0} \mathbf{~ m m} \mathbf{~ H g}\end{array}$ & $\begin{array}{c}\mathbf{E}(\mathbf{k P a}) \\
\mathbf{1 0 0 - 1 2 0} \mathbf{~ m m} \mathbf{~ H g}\end{array}$ \\
\hline Native Ao & $516.08 \pm 126.21$ & $704.02 \pm 170.67$ & $967.45 \pm 164.60$ \\
\hline SFA & $615.95 \pm 50.88$ & $798.46 \pm 25.26$ & $1158.35 \pm 127.52$ \\
\hline EETE & $683.29 \pm 65.87$ & $932.63 \pm 257.18$ & $1232.79 \pm 586.79$ \\
\hline ETE & $902.39 \pm 86.49$ & $1138.16 \pm 216.23$ & $1261.35 \pm 235.76$ \\
\hline
\end{tabular}

Table 2.9.

The $p$ significance levels for differences of strain between the specimens

\begin{tabular}{|c|c|c|c|}
\hline Specimens & $\boldsymbol{\varepsilon}, \boldsymbol{\%}(\mathbf{8 0} \mathbf{~ m m ~ H g})$ & $\boldsymbol{\varepsilon}, \%(\mathbf{1 0 0} \mathbf{~ m m ~ H g})$ & $\boldsymbol{\varepsilon}, \%(\mathbf{1 2 0} \mathbf{~ m m ~ H g})$ \\
\hline Ao / IZA & $p=0.476$ & $p=0.404$ & $p=0.366$ \\
\hline Ao / PAGG & $p=0.015$ & $p=0.0125$ & $p=0.0137$ \\
\hline Ao / AGG & $p=0.0079$ & $p=0.0064$ & $p=0.0067$ \\
\hline IZA / & $p=0.0058$ & $p=0.006$ & $p=0.0068$ \\
PAGG & & & \\
\hline PAGG / & $p=0.0094$ & $p=0.0063$ & $p=0.0082$ \\
AGG & & & \\
\hline
\end{tabular}


Table 2.10.

The $p$ significance levels for differences of the modulus of elasticity between the specimens

\begin{tabular}{|c|c|c|c|}
\hline Specimens & $\begin{array}{c}\mathbf{E} \mathbf{~ k P a} \\
(\mathbf{6 0 - 8 0} \mathbf{~ m m} \mathbf{H g})\end{array}$ & $\begin{array}{c}\mathbf{E} \mathbf{~ k P a} \\
(\mathbf{8 0 - 1 0 0 ~} \mathbf{~ m m} \mathbf{H g})\end{array}$ & $\begin{array}{c}\mathbf{E ~ k P a} \\
(\mathbf{1 0 0 - 1 2 0} \mathbf{~ m m} \mathbf{~ H g})\end{array}$ \\
\hline Ao / IZA & $p=0.113$ & $p=0.379$ & $p=0.358$ \\
\hline Ao / PAGG & $p=0.021$ & $p=0.173$ & $p=0.3$ \\
\hline Ao / AGG & $p=0.0006$ & $p=0.044$ & $p=0.25$ \\
\hline IZA / PAGG & $p=0.168$ & $p=0.275$ & $p=0.441$ \\
\hline PAGG / AGG & $p=0.022$ & $p=0.227$ & $p=0.478$ \\
\hline
\end{tabular}




\section{DISCUSSION}

Our data show that the prevalence of AoCo in Latvia does not significantly differ from other European countries. Coarctation of the aorta is a difficult CHD to screen for and diagnose before birth because it develops completely only after the closure of the ductus post-natally. The study by Khoshnood B. et al. (2005) showed an increase in prenatal diagnostics of AoCo up to $40 \%$. According to the data from Matsui H. and Mellander M. (2008) in $32 \%$ of the cases, infants with isolated AoCo who were admitted to hospital for surgical correction had a pre-natally suspected diagnosis. However, the cases more likely to be diagnosed antenatally tend to be more severe and more often are connected with a concomitant intracardiac pathology.

This study shows that $36 \%$ of the babies with AoCo were still referred only after discharge from the birth hospital and in a quarter of the cases (27\%), the doctor did not suspect CHD as the cause of the deterioration of the infant. Early referral correlated with other concomitant intracardiac lesions, which allowed the diagnosis of CHD, due to murmur and signs of cardio-vascular insufficiency. In cases of isolated AoCo, half of the patients had a late diagnosis.

Aamir T. et al. (2007) found coarctation to be the most common delayed diagnosis with the age at final diagnosis of 3 days to 6 months (average delay in diagnosis 6 weeks). These newborns and infants had multiple other diagnoses before the final diagnosis was reached and $40 \%$ of them ended up in an emergency room. The cost of a nation-wide echocardiographic screening programme has been estimated to be too high and it would not be as effective due to transitory haemodynamic changes in the early neonatal period. In the past few years, researchers have suggested pulse oxymetry as an aid to clinical examination for the detection of ductus dependent CHD in neonates. De-Wahl 
Granelli A. et al. (2009) recommended measurements of preductal (right hand) and postductal (foot) saturation. The baby is considered to be screening positive if both measurements are below $95 \%$ or there is a difference of $3 \%$ or greater between the hand and foot, in three repeated measurements. This, however, is not sensitive enough to serve as an independent tool for ductus dependent systemic circulation. Another study by de-Wahl Granelli A. and Östman-Smith A. (2007) suggested measurements of the non-invasive peripheral perfusion index (PPI) on the right hand (preductally) and either foot (postductally). A preor postductal PPI below the $5^{\text {th }}$ percentile (cut off 0.7 ) could be used to increase the detection of left heart obstructive lesions in neonates. In combination with a physical examination including the palpation of femoral pulses it could be used as a screening method in maternity units with echocardiography performed for those screened positive. The palpation of femoral pulses in our country is mandatory during the examination of every newborn infant within the first 24 hours of life in maternity hospital (The Latvian Association of Neonatologists, guidelines 2010), but is not included as obligatory in the examination of newborn before discharge or in the neonatal examination for the general practitioner at home. A substantial numbers of babies with ductus dependent systemic circulation have poor or absent femoral puses as a major alerting sign, so the omition of the palpation of the femoral pulse in newborn decreases the possibility of early diagnosis.

AoCo in neonates and infants during the last decade is still associated with a high mortality, which is affected by such factors as a perioperative condition and intensive care, concomitant intracardiac pathology and hypoplasia of the aortic arch. $95 \%$ of the patients were alive at the end of the study period within the group with isolated coarctation, 59\% in combination with VSD and $67 \%$ of the complex AoCo $(p=0.001)$. The overall survival was $81 \%$. Hoimyr H. et al. (2006, Denmark) in the study with the one of the longest follow-up periods up to 40 years (median 29 years), where only $8 \%$ of children within the first year 
of life of 229 patients were included, showed an overall survival of 69\%. The patients without concomitant intracardiac pathologies who survived surgical correction of the lesion were subject to 3.4 times higher long term morbidity and mortality in comparison with their healthy peers in the population and the method of surgical correction had no impact on the outcomes. Kaushal S. et al. (2009, USA) in the study where AoCo was corrected using EETE in 201 patients with the exclusion of complex AoCo patients, showed an overall mortality of $4 \%$ (follow-up period median 4.3 years). Barreiro C. J. et al. (2007, USA) in the study with 119 neonates with isolated AoCo, described an overall mortality of $10 \%$.

There is a high incidence of recoarctation of the aorta in patients operated on due to AoCo as neonates and infants (25\%). The recoarctation rates did not differ significantly between surgical methods used. The literature shows recoarctation rates of $7-29 \%$ for the patients operated on as neonates and infants. Karamlau et al. (2009, Canada) described recoarctation in $14 \%$ of infantsoperated on at the age of 2-69 days. Sudarshan C. D. et al. (2006, Australia) showed a recoarctation rate of $29 \%$ in newborn babies operated on with a weight up to $2 \mathrm{~kg}$. Haager et al. (2009, Germany) found $24 \%$ of AoreCo in infants with isolated AoCo. Fruh et al. (2011, Switzerland) demonstrated AoreCo in $11 \%$ of infants with AoCo corrected at the age of 0-6 months, but Fiore et al. (2005, USA) observed AoreCo in $18 \%$ of the infants who had undergone surgical correction of AoCo within first 40 days of life. We observed the development of AoreCo during the first year following surgery in $60 \%$ of the cases. Kaushal S. et al. (2009, USA) described AoreCo in $75 \%$ of the cases during the first year following primary correction.

The data from the literature confirm the surgical correction of AoCo to be the basic method for neonates and small infants due to the fewer complications and need for reinterventions (Kenny et Hijazi, 2011; Fiore et al., 2005, Fruh et al., 2011; Peres et al., 2010). The main goal of the surgical correction of AoCo 
is an adequate reconstruction of the aortic arch followed by the subsequent correction of associated intracardiac pathologies. There are different mechanisms for the developement of AoreCo in the cases of the various surgical methods used. In cases of ETE, the development of AoreCo is associated with incomplete resection of ductal tissue and disturbances in the growth of circular suture lines. In cases of SFA, the formation of AoreCo might be connected with remaining ductal tissue after an incomplete resection. An early restenosis in small infants, following primary balloon angioplasty of AoCo, is associated with elastic recoil of the ductal tissue surrounding the coarctation zone. The balloon angioplasty and/or stenting are recommended as a succesfull method in older children and cases of recoarctation (Golden et Hellebrand, 2007; Kenny et Hijazi, 2011; Reich et al., 2008; Rodes-Cabau et al., 2007).

At the time of recoarctation the patients showed hypertrophy of the left ventricle on an echocardiography which gradually decreased after the relief of stenosis, but the LVMi/height ${ }^{2.7}$ at the end of the study remained higher in comparison with those without recoarctation and the control group. Different authors give different cutoff values in defining left ventricle (LV) hypertrophy in children and adolescents. LV hypertrophy in adults is considered as an LVMi/height ${ }^{2.7}$ exceeding $51 \mathrm{~g} / \mathrm{m}^{2.7}$ (De Simone et al., 1995). Foster et al. (2008) showed the same numbers as the $95^{\text {th }}$ percentile for healthy children without serious differences between the genders up to the age of 12 years. Daniels S. R. et al. (1995) reported $38.6 \mathrm{~g} / \mathrm{m}^{2,7}$ as the $95^{\text {th }}$ percentile for a healthy pediatric population. Khoury P. R. et al. (2009) found that for patients less than 9 years old, the LVMi/height ${ }^{2.7}$ varied with age, and percentiles for newborns and infants were approximately double the levels for older children and adolescents: the $95^{\text {th }}$ percentile ranged from $80 \mathrm{~g} / \mathrm{m}^{2.7}$ for neonates to $40 \mathrm{~g} / \mathrm{m}^{2.7}$ for 11 year olds. Left ventricle hypertrophy together with arterial hypertension is a cardio-vascular risk factor that increases the risk for 
myocardial infarction, stroke, and death and can be modified (Bauml, 2010). Small infants and children should be followed up frequently after surgical correction of AoCo to exclude development of recoarctation and the need for reintervention.

The echocardiographic protocol for the follow up of the study group was supplemented by an analysis of abdominal aortic PWD Doppler flows. Echocardiography has become the primary non-invasive method used in the assessment of AoCo and recoarctation. Clinical stratification of the severity of AoCo and AoreCo is based on the Ao pressure gradient, clinical symptoms, and the degree of luminal narrowing. Suboptimal alignment of the CWD doppler beam with the flow jet may lead to an underestimation of the severity of recoarctation. Silvilairat et al. (2008) showed a systolic to diastolic velocity ratio (PWD S/D) $<3.6$ to be the predictor of clinical coarctation status. In this study PWD S/D ratios were markedly decreased in those having clinically significant recoarctation which is consistent with these data. Pulsed wave doppler signals in the abdominal Ao are easy to obtain and serve as additional information to continuous wave doppler flow profile in descending Ao, to confirm the recoarctation.

The decision on the type and timing of surgical intervention or reintervention usually relies on detailed measurements of cardiac structures. Liu J. Y. J. et al. (2010) found no correlation between the size of the proximal Ao arch at the last follow up and its size before the repair or the technique used. One third of the patients in their study kept a small proximal arch. In our study, the mean $\mathrm{z}$ values of the proximal transverse Ao arch at the end of the study did not statistically differ from the control group but there were still 5 pacients with a $z$ score of $-2.28 \pm 0.15$ in the study group with CWD Pg max. $15.2 \pm 5.8 \mathrm{~mm}$ Hg. 4 of these patients had undergone SFA but one anastomosis ETE. These patients had no arterial hypertension at the end of the study but they might be at risk of developing hypertension in the future. There might be differences 
between the surgical techniques and the surgeons in their ability to enlarge the transverse Ao arch. Further additional studies are needed to find out whether such patients might be better operated on through strenotomy eith extended arch repair, because remodeling of the hypoplastic proximal transverse arch might not occur after conventional coarctation repair in patients with moderately hypoplastic proximal transverse arches (Liu et al., 2010; Rakhra et al., 2013; Sakurai et al., 2012).

Our data showed a significantly smaller isthmus in the study group patients in the absence of clinically significant recoarctation in comparison with controls ( $p=0.0001)$. Puranik et al. (2009) in magnetic resonance surveillance 20 years following AoCo correction at an age of up to 2 years detected significant rates of recoarctation (34\% of mild and, $34 \%$ moderate to severe recoarctations). The authors suggested more frequent non-invasive surveillance with a clinical examination plus a magnetic resonance examination as the most cost-effective method for these patients.

The stiffness of the arterial wall is described as an independent risk factor for acute cardio-vascular events, acute coronary syndrome, intracranial haemorrhage and mortality (Bassareo et al., 2009; Ou et al., 2008). Clinical trials have shown that even normotensive patients, after coarctation repair, have markedly increased left ventricle mass as a sequel to increased aortic stiffness and pulse wave velocities, decreased central aortic dispensability and compliance. Our data show a significant difference between the biomechanical properties of the native aorta and different anastomoses used for the surgical correction of coarctation with the strain of the surgically corrected aorta being much smaller. The native aorta in neonates and small infants has significant strain properties which explain the elastic recoil after the primary balloon angioplasty with subsequent recoarctation in this age group. The modulus of elasticity of the native aorta increases with an increase in the inner pressure but these strain properties are limited at the level of suture lines. The differences 
between the biomechanical properties of the native aorta and the aorta following surgical correction are less prominent within the range of physiological arterial pressure for the age and more obvious with an increase in the inner pressure above the physiological limits. The differences were most pronounced in cases of anastomosis ETE which are connected with circular suture lines. The differences were less prominent in cases of EETE, but anastomosis SFA was the closest to the native aorta. That is consistent with the findings of elevated arterial pressure during physical activities in otherwise normotensive patients following successful coarctation repair.

The data were acquired from in vitro study, so the limitation is the difference between experimental results and real patients, the comperatively small number of experiments and the constant longitudinal tension which is not completely physiological.

The comparison of biomechanical to clinical data showed a decrease in the maximum CWD doppler gradient in descending aorta detected by echocardiography early post operation in cases of different surgical techniques: ETE CWD Pg max. $25.53 \pm 9.4 \mathrm{~mm} \mathrm{Hg}$, EETE $17.64 \pm 4.5 \mathrm{~mm} \mathrm{Hg}$, but SFA $15.95 \pm 6.6 \mathrm{~mm} \mathrm{Hg}$. Long term follow-up data showed no statistically significant recoarctation rate differences between the groups of different techniques: $18 \%$ ETE group, 29\% SFA group and 25\% EETE group ( $p=0.67)$. The priorities of SFA are less tension at the level of suture lines, the chance to avoid circular sutures and the growth potential of the autologos tissue, but the drawback is the need to scarify the left subclavian artery therefore many centres use EETE as a method of choice in cases of infantile AoCo with hypoplasia of the isthmus and sometimes hypoplastic transverse Ao arch. Reinhart Z. et al. (2012, United Kingdom) described less recoarctations rates and lower flow velocities in magnetic resonance in adults who had undergone surgical correction of AoCo in childhood with SFA versus ETE. In cases of EETE, a large amount mobilization of the aortic arch and descending aorta is performed which might 
not be an advantage in critically ill neonates. Surgical strategy is usually chosen by the surgeon guided by the individual features of the shape and size of the patient's aortic arch. 


\section{CONCLUSIONS}

1. The prevalence of coarctation of the aorta in neonates in Latvia between 2000 to 2010 was $3.4 \pm 1.3$ per 10.000 live born infants.

2. The cumulative survival in infants with isolated coarctation significantly exceeded the survival of patients with coarctation and concomitant intracardiac pathology $(p=0.001)$.

3. Echocardiographic findings of the infants with coarctation of the aorta show a prevalence of infantile coarctation with variable hypoplasia of the aortic arch.

4. The pulse wave dopplerographic measurements in the abdominal aorta give additional information about the obstruction of the aortic arch.

5. Coarctation of the aorta should be looked on as a complicated cardiovascular syndrome with a need for life-long follow up, due to the risk of multiple complications in the long term (recoarctation, arterial hypertension, formation of aortic aneurysm).

6. From a biomechanical point of view, anastomosis with a left subclavian flap is the closest to the native aorta followed by extended anasomosis end-toend , but anastomosis end-to-end is the stiffest and can cause hemodynamic disturbances.

7. Surgical correction of coarctation of the aorta is the basic method in neonates and small infants with an extended anastomosis end-to-end as a method of choice, but subclavian flap aortoplasty can be still used in cases when the reconstruction of the arch is difficult in low weight and critically ill neonates. Subclavian flap aortoplasty does not cause significant imparements of the left upper extremity in the medium follow up period. 


\section{PRACTICAL SUGGESTIONS}

1. There are grounds for commencing pulse oxymetry screening of ductus dependent congenital heart diseases in neonates before discharge from the birth hospital and to work out more detailed guidelines for clinical assessment of the cardio-vascular system of neonates including palpation of femoral pulses for general practitioners working with newborn and infants.

2. Patients, after surgical correction of coarctation, are in need of regular, systematic out-patient follow-up, including clinical and detailed echocardiographic examination to promote the timely diagnostics of complications (algorithm for the treatment/follow-up of the patients with AoCo) (Figure 2.11.).

3. Pulse wave dopplerographic measurements should be included in a rutine examination protocol for the examination of patients who had undergone correction of coarctation of the aorta, for timely recognition of recoarctation. 


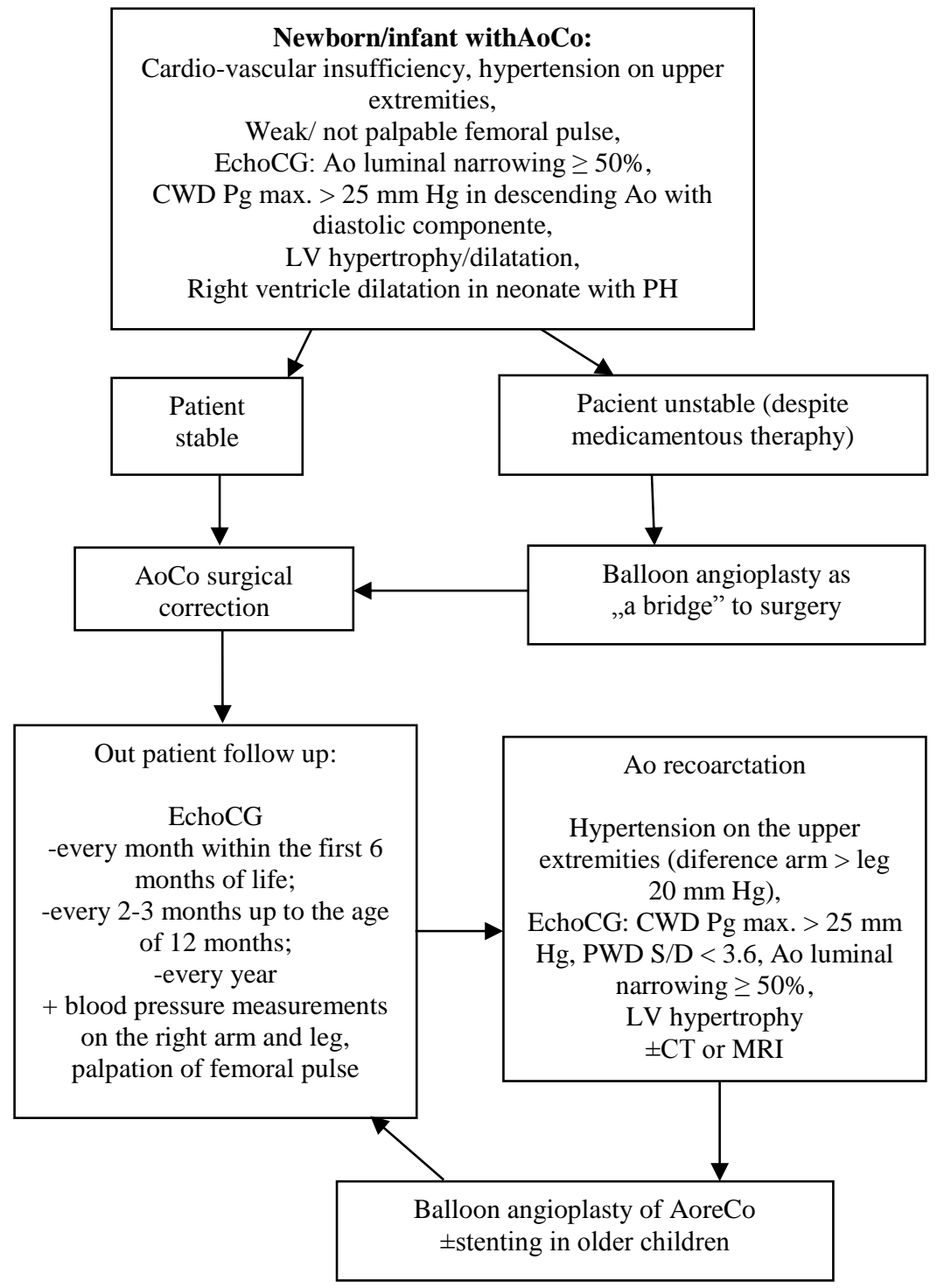

Figure 2.11. Algorithm for the treatment/follow up of patients with AoCo 


\section{PUBLICATIONS AND PRESENTATIONS ON THE RESEARCH THEME}

\section{Publications (scientific articles) on the theme of research}

1. Teivane E., Sikora N., Ozolins V., Smits L., Bergmane I., Lacis A., Kasyanov V. Biomechanical Properties of the Aorta in Neonates and Infants. Riga Stradins University Collection of Scientific Papers, 2010, 6065.

2. Ligere E., Sikora N., Ozolins V., Smits L., Bergmane I., Lacis A., Kasyanov V. Biomechanical Properties of the Aorta in Neonates and Infants. Book chapter: A. Öchsner et al. (Eds.) Analysis and design of Biological Materials and Structures, Advanced Structured Materials 14, Springer-Verlag Berlin Heidelberg, 2012. DOI: 10.1007/987-3-642-221316_10.

3. Ligere E., Lacis A., Smits L., Ozolins V., Sikora N., Bergmane I., Lubaua I., Lace I., and Feldmane L. Aortic coarctation repaired within the first year of life: an 11 year review. Acta Chirurgica Latviensis, 2011 (11), 98-103. DOI 10.2478/v10163-012-0019-3.

4. Ligere E., Lacis A., Smits L., Ozolins V., Sikora N., Bergmane I., Lubaua I., Lace I. Timely and late recognition of the coarctation of the aorta in neonates and small infants. Riga Stradins University Collection of Scientific Papers, 2011, 54-60.

5. Ligere E., Ozolins V., Smits L., Sikora N., Melderis I., Feldmane L., Lacis A., Kasyanov V. The Biomechanical Properties of the Different Modalities of Surgically Corrected Coarctation of the Aorta in Neonates and Infants. World Academy of Science, Engineering and Technology Issue 66, June 2012, 60-63. pISSN 2010-376x, eISSN 2010-3778. 
6. Ligere E., Lubaua I., Lace I., Bergmane I., Knauere V., Ozolins V., Smits L., Sikora N., Lacis A. Echocardiographic Follow-up After Surgical Correction of the Aortic Coarctation within the First Year of Life in Latvia. (Accepted to Journal Proceedings of the Latvian Academy of Sciences Section B).

\section{Conference theses on the theme of research}

1. Teivane E., Lacis A., Ozolins V., Smits L., Sikora N., Bergmane I. Surgical treatment of aortic coarctation within the first year of life: a 10 year review (clinical, surgical, biomechanical aspects). 44th Annual Meeting of the Association for European Paediatric Cardiology, AEPC with joint sessions with the Japanese Society of Pediatric Cardiology and Cardiac Surgery, Cardiology in the Young, Volume 20, Supplement 2, p. 71. Poster. Innsbruck, Austria, May 26-29, 2010.

2. Teivane E., Sikora N., Ozoliņš V., Šmits L., Bergmane I., Lācis A., Kasjanovs V. The biomechanical properties of the aorta in neonates and infants. Scientific conference of Riga Stradins University 2010, Poster.

3. Teivane E., Sikora N., Ozolins V., Smits L., Bergmane I., Lacis A., Kasyanovs V. Biomechanical Properties of the Aorta in neonates and Infants. 4th International Conference on Advanced Computational Engineering and Experimenting, Paris, France, July 8-9, 2010. Poster.

4. Ligere E., Lācis A., Šmits L., Ozoliņ̌š V., Sikora N., Lubaua I., Lāce I., Bergmane I. Aortic coarctation in newborn and infants. Scientific conference of Riga Stradins University 2011, Poster.

5. Ligere E., Lacis A., Smits L., Ozolins V., Sikora N., Bergmane I., Lubaua I., Lace I. The recognition of Coarctation of the Aorta in Neonates and Small Infants and its Relation to the Course of the Disease and the 
Outcomes. 45th Annual Meeting of the Association for European Paediatric Cardiology, AEPC with joint sessions with the Japanese Society of Pediatric Cardiology and Cardiac Surgery, Cardiology in the Young, Volume 21, Supplement 1, p. 122. Poster. Granada, Spain, May 18-21, 2011.

6. Ozoliņš V., Šmits L., Sikora N., Bergmane I., Teivāne E., Lācis A. Baloon angioplasty of the recoarctation of the aorta in pediatrics. Scientific conference of Riga Stradins University, 2009.

\section{Presentations at scientific-practical conferences on the theme of research}

1. Teivane E. Non invasive methods of examination in pediatric cardiology. Clinical conference of the University Hospital for Children, 12.12.2008.

2. Teivane E. Actualities in pediatric cardiology. Meeting of the Latvian Association of Paediatricians, Daugavpils, October 30, 2009.

3. Teivane E. Aortic carctation in neonates and infants. Clinical conference of University Hospital for Children, December 10, 2009.

4. Teivane E., Lacis A., Lubaua I., Smits L., Ozolins V., Sikora N., Bergmane I., Lace I. The possibilities and perspectives of examination and treatment in the Clinics for Paediatric Cardiolgy and Cardiac Surgery. $1^{\text {st }}$ Interdisciplinary Conference of the University Hospital for Children, October 1, 2009.

5. Lace I., Ligere E. Arterial hypertension and coarctation of the aorta as one of the causes in pediatrics. Seminar of Latvian Association of Sports Medicine, Riga, May 19, 2011.

6. Ligere E. Aortic coarctation as ductus dependent congenital heart disease. Meeting of the Latvian Association of Pediatric Cardiology, April 8, 2011. 
7. Ligere E., Lubaua I., Lāce I., Lācis A., Kasjanovs V. Echocardiographic assessment of aortic coarctation in neonates and infants. Scientiffic conference of the Riga Stradins University, 2012.

8. Ligere E. The echocardiographic assessment of aortic arch and coarctation of the aorta in children. The meeting of Echocardiography of the Latvian Association of Cardiology, May 11, 2012.

9. Ozolins V., Ligere E., Lacis A., Smits L., Lubaua I. Surgical Outcome after Correction of the Aortic Coarctation in Neonates and Infants. The 12th Conference of the Baltic Association of Paediatric Surgeons, May 17-19, 2012. Riga.

10. Ligere E., Ozolins V., Smits L., Sikora N., Melderis I., Feldmane L., Lacis A., Kasyanov V. The Biomechanical Properties of the Different Modalities of Surgically Corrected Coarctation of the Aorta in Neonates and Infants. ICBBE 2012: International Conference on Biomechanics and Biomedical EngineEngineering, Denmark, Copenhagen, June 11-12, 2012. 